\title{
The selectivity, voltage-dependence and acid sensitivity of the tandem pore potassium channel TASK-1: contributions of the pore domains
}

\author{
K. H. Yuill • P. J. Stansfeld • I. Ashmole • \\ M. J. Sutcliffe • P. R. Stanfield
}

Received: 2 April 2007 / Accepted: 25 April 2007 / Published online: 1 June 2007

(C) Springer-Verlag 2007

\begin{abstract}
We have investigated the contribution to ionic selectivity of residues in the selectivity filter and pore helices of the P1 and P2 domains in the acid sensitive potassium channel TASK-1. We used site directed mutagenesis and electrophysiological studies, assisted by structural models built through computational methods. We have measured selectivity in channels expressed in Xenopus oocytes, using voltage clamp to measure shifts in reversal
\end{abstract}

Electronic supplementary material The online version of this article (doi:10.1007/s00424-007-0282-7) contains supplementary material, which is available to authorised users.

K. H. Yuill, P. J. Stansfeld and I. Ashmole contributed equally to this paper.

K. H. Yuill $\cdot$ I. Ashmole $\cdot$ P. R. Stanfield $(\bowtie)$

Molecular Physiology Group, Department of Biological Sciences,

University of Warwick,

Coventry CV4 7AL, UK

e-mail: p.r.stanfield@warwick.ac.uk

P. J. Stansfeld

Department of Cell Physiology and Pharmacology,

University of Leicester,

P.O. Box 138, Leicester LE1 9HN, UK

Present address:

P. J. Stansfeld

SBCB, Department of Biochemistry,

University of Oxford,

South Parks Road,

Oxford OX1 3QU, UK

\section{J. Sutcliffe}

Manchester Interdisciplinary Biocentre, University of Manchester, 131 Princess Street,

Manchester M1 7DN, UK

K. H. Yuill

Department of Pharmacy and Pharmacology, University of Bath, Bath BA2 7AY, UK potential and current amplitudes when $\mathrm{Rb}^{+}$or $\mathrm{Na}^{+}$replaced extracellular $\mathrm{K}^{+}$. Both $\mathrm{P} 1$ and $\mathrm{P} 2$ contribute to selectivity, and most mutations, including mutation of residues in the triplets GYG and GFG in P1 and P2, made channels nonselective. We interpret the effects of these-and of other mutations - in terms of the way the pore is likely to be stabilised structurally. We show also that residues in the outer pore mouth contribute to selectivity in TASK-1. Mutations resulting in loss of selectivity (e.g. I94S, G95A) were associated with slowing of the response of channels to depolarisation. More important physiologically, $\mathrm{pH}$ sensitivity is also lost or altered by such mutations. Mutations that retained selectivity (e.g. I94L, I94V) also retained their response to acidification. It is likely that responses both to voltage and $\mathrm{pH}$ changes involve gating at the selectivity filter.

Keywords Potassium channel - Ionic selectivity · $\mathrm{pH}$ sensitivity . Voltage dependence

\section{Introduction}

Sequencing and functional studies have uncovered a great diversity among potassium ion channels, with several gene families now established. Members of the tandem pore $\left(\mathrm{K}_{2 \mathrm{P}}\right)$ or $K C N K$ family $[18,29,41]$ contribute to the setting of resting potentials of a wide variety of cells, a function they may share with members of other ion channel families, including members of the inward rectifier or Kir family [49] and of the CLC family [21]. Although tandem pore channels are often described as leakage channels, it is known that they do not act simply as open conduits for the flux of $\mathrm{K}^{+}$across the membrane. Single channel recording shows that channels spend time shut in physiological conditions so that open state probability $\left(P_{\text {open }}\right)$ may be 
very much less than unity (e.g. [26]). Further, many physiological factors modulate channel activity, altering $P_{\text {open }}$. These factors include $\mathrm{pH}$, protein phosphorylation, arachidonic acid, membrane stretch, inositol phospholipids, $\mathrm{Ca}^{2+}$ and temperature $[11,12,18,41]$. In addition, tandem pore channels either are $[32,56]$ - or may under certain circumstances $[5,37]$ be - gated by voltage.

In the tandem pore $(K C N K)$ family, channel subunits each possess two pore (P-)regions in tandem. The primary structure of these two pore regions is not identical, and although both regions are likely to contribute to ionic selectivity, the contributions of the two differ in subtle ways (see, e.g. [7]). Classically, the P-region of $\mathrm{K}^{+}$channels contains the consensus sequence TxxTxGYG, but this consensus does not hold firmly in the tandem pore family. The peptide bonds between the last five residues of this sequence contribute a series of rings of carbonyl oxygen atoms through which $\mathrm{K}^{+}$ions move (e.g. [15]). Set at the correct distance, these form binding sites for $\mathrm{K}^{+}$. The side chain hydroxyl of the second $\mathrm{Thr}$ residue of the motif also contributes to the innermost binding site. This mechanism of selectivity, first proposed by Bezanilla and Armstrong [3], with carbonyl oxygens acting as surrogates for the oxygens of water in solution, is now universally accepted following the solution of the structure of the bacterial $\mathrm{K}^{+}$ channel KcsA by X-ray crystallography [15]. In this paper, we investigate the effects of altering residues in the pore regions of the P1 and P2 domains on ionic selectivity of TASK-1.

TASK-1 is important physiologically, as it is sensitive to changes of extracellular $\mathrm{pH}$ and is shut in acid conditions $[16,24,28]$. Regulation by extracellular $\mathrm{pH}$ has suggested roles in the maintenance of acid-base balance, for example in the regulation of respiration by central [2] and peripheral chemoreceptors [6]. The sensitivity to a change of extracellular $\mathrm{pH}$ is thought to be endowed by a His residue (H98) in the first (P1) of two tandem pore regions $[1,26$, $33,38,44]$. This residue lies at the outer mouth of the pore, at a position occupied by aspartate in P2 of TASK-1 and in the single pore region of many members of other $\mathrm{K}^{+}$ channel families. However, the abolition of $\mathrm{pH}$ sensitivity in $\mathrm{H} 98 \mathrm{~N}$, for example, is not complete in TASK-1, and other residues may well contribute to acid sensing [1, 38]. These channels also show voltage dependence, consistent with an increased open probability under depolarisation [32]. Both voltage dependence and $\mathrm{pH}$ sensitivity of TASK-1 are affected by extracellular $\left[\mathrm{K}^{+}\right]$[32]. We have therefore considered, in making mutations of the pore region, whether the responses of TASK-1 to depolarisation and to acidification belong to the class of gating thought to occur at the selectivity filter (see, e.g. $[4,54]$ ).

We show that changes in the structure of the pore alter ionic selectivity, as anticipated, and we consider our findings in terms of a structural model of TASK-1. Changes in the structure of the pore do indeed also alter the response both to membrane potential and to acidification. Mutations of the selectivity sequence that abolish selectivity appear to slow the response to depolarisation and reduce acid sensitivity. We consider that these responses are likely to involve a change in the conformation of the selectivity filter.

\section{Materials and methods}

\section{Molecular biology}

Experiments used murine TASK-1, cloned from mouse total brain RNA [55]. In a few experiments, we used a concatameric dimer of TASK-1, whose construction has also been described previously [55]. Mutants were generated by the QuikChange method (Stratagene), and all mutations were verified by sequencing the entire mutant complementary DNA, using the molecular biology service in the Department of Biological Sciences, University of Warwick. We found TASK-1 expression difficult to achieve routinely in HEK293 or CHO cells and accordingly used expression in Xenopus oocytes. Complementary RNAs (cRNAs) were synthesised in vitro from MluI-linearised pBF vector, using SP6 polymerase (Ambion).

\section{Electrophysiology}

Electrophysiological recordings were carried out on TASK-1 channels expressed in oocytes obtained from Xenopus frogs anaesthetised by immersion in $0.3 \%(w / v)$ MS222 and killed by destruction of the brain and spinal cord. Oocytes were injected with up to $50 \mathrm{ng}$ cRNA and recordings were made $1-5$ days after injection.

We used a GeneClamp 500B amplifier, a Digidata $1322 \mathrm{~A}$ interface and pClamp version 8.2 software (all Axon Instruments, Foster City, CA) to measure ionic currents under two-electrode voltage clamp. Impaling borosilicate glass microelectrodes were used backfilled with $3 \mathrm{M} \mathrm{KCl}$. Currents were filtered at $2 \mathrm{kHz}$ and digitised at $10 \mathrm{kHz}$. Analysis also used pClamp software and curve fitting used this software or Sigmaplot 2001 or version 9.0.

Experiments were carried out at room temperature $\left(\sim 20^{\circ} \mathrm{C}\right)$ using extracellular solutions containing permeant cations at $70 \mathrm{mM}$. The $\mathrm{K}^{+}$solution contained $\left(\mathrm{mmol} \mathrm{l}^{-1}\right)$ : $70 \mathrm{KCl}, 26 \mathrm{~N}$-methyl-D-glucamine, $1 \mathrm{CaCl}_{2}, 1 \mathrm{MgCl}_{2}$, $10 \mathrm{~N}$-2-hydroxyethylpiperazine- $N$ '-2-ethanesulfonic acid 
(HEPES), $\mathrm{pH}$ adjusted using $\mathrm{HCl}$. In some experiments, we omitted $\mathrm{CaCl}_{2}$ and $\mathrm{MgCl}_{2}$ from our experimental solutions to test whether voltage dependence was generated by reversal of voltage-dependent blockage by divalent cations or whether currents activated by $\mathrm{Ca}^{2+}$ entry materially affected our results.

In experiments to measure ionic selectivity against $\mathrm{Rb}^{+}$ and $\mathrm{Na}^{+}$, we replaced $\mathrm{KCl}$ in the experimental (extracellular) solution by $\mathrm{RbCl}$ or $\mathrm{NaCl}$. As is conventional, permeability ratios $\left(P_{\mathrm{X}} / P_{\mathrm{K}}\right)$ were measured from the shift in reversal potential $\left(\Delta E_{\mathrm{rev}}\right)$ occurring when $\mathrm{Rb}^{+}$or $\mathrm{Na}^{+}$ replaced $\mathrm{K}^{+}$in the extracellular solution, that is from

$\Delta E_{\mathrm{rev}}=\frac{\mathrm{RT}}{F} \cdot \ln \frac{P_{X}\left[X^{+}\right]_{o}}{P_{K}\left[K^{+}\right]_{o}}$

where $X^{+}$represents either $\mathrm{Rb}^{+}$or $\mathrm{K}^{+}$. The experiments were carried out at $\mathrm{pH} 7.8$ to maximise $\mathrm{pH}$-sensitive currents so far as possible. As small endogenous currents are found in oocytes, the values given for $P_{\mathrm{Na}} / P_{\mathrm{K}}$ (e.g. for wild type) correspond to an upper limit.

To test $\mathrm{pH}$ sensitivity, we used $10 \mathrm{mM}$ HEPES ( $\mathrm{pH}$ adjusted using $\mathrm{HCl}$ ) for solutions at $\mathrm{pH} 7.0$ to 8.5, piperazine-1,4-bis-2-ethanesulfonic acid for $\mathrm{pH}_{\mathrm{o}} 6.5$, and 2-(N-morpholino)ethanesulfonic acid for $\mathrm{pH}_{\mathrm{o}}$ 6.0. To analyse, we fitted the responses to $\Delta \mathrm{pH}_{\mathrm{o}}$ using an expression that assumes reduction in current is proportional to the fractional protonation of a regulating site:

$y=a \cdot\left\{1+\frac{\left[H^{+}\right]_{o}}{K_{a}}\right\}^{-1}+b$

In this study, $y$ is the current, normalised to its value at $\mathrm{pH}_{\mathrm{o}} 8.5$, and $K_{a}$ is the equilibrium constant (we give the $\mathrm{p} K_{a}$ in the text of this paper). $a /(a+b)$ is the fraction of the current that is sensitive to acidification, with $b /(a+b)$ the fractional current remaining at low $\mathrm{pH}_{\mathrm{o}}$. We set $b$ to zero if its fitted value was less than 0.05 (as in wild-type channels).

We made statistical comparison of experimental results from mutants with those from wild type using analysis of variance with a Dunnett multiple comparisons test. The results of this comparison are given in Tables 1 and 2. Comparison among mutants used a Tukey-Kramer multiple comparisons test. Additional results detailing the relative permeabilities (Supplementary Table 1) and $\mathrm{pH}$ sensitivities (Supplementary Table 2) are given in supplementary material.

Sequence analysis and homology modelling

The secondary structure and transmembrane topology for murine TASK-1 (Swissprot accession code 035111) were predicted using the PSI-prediction server [36]. Homology modelling was used to predict structures of the transmem- brane domains. KcsA was chosen as the primary structural template for TASK-1 (protein data bank [PDB] accession code $1 \mathrm{~K} 4 \mathrm{C}$ [57]). We used ClustalX to align two copies of the sequence of $\mathrm{Kcs}$ - modified to resemble a dimer by merging two copies of the monomer-with the sequence of the dimeric murine TASK-1 (Supplementary Fig. 1).

The homology models of TASK-1 were created using Modeller 6v2 [46]. For each set of ten TASK-1 models generated, the lowest energy model was selected. Initial structures of TASK-1 were based on KcsA, although these models were modified to incorporate the M2-M3 linker and the linker between M1 and P1, which is also known as the self-interacting domain [29, 30]. The orientation by which M2 is connected to M3 may only be hypothesised. Based on the distances between the outer and inner helices of the $\mathrm{K}^{+}$channel crystal structures, including KcsA (PDB accession code: 1K4C), KirBac1.1 (1P7B) and KvAP (1ORQ), the minimum M2-M3 separation was obtained in a clockwise rotation, as viewed from above. The orientation and secondary structure of the M2-M3 linker, therefore, shares equivalence with the slide helix of KirBac1.1. To incorporate the M2-M3 linker, the KirBac1.1 structure (1P7B) was aligned with the structure of KcsA, with KirBac1.1 used to model both the M2-M3 linker and M3 helix.

The self-interacting domain was modelled based on an equivalent region of the crystal structure of the alkyl hydroperoxide reductase subunit F (AHPF; 1HYU) [53], which shares sequence and secondary structural similarity. The domain was connected to the top of the channel based on four restraints: (1) The $\mathrm{N}$ terminus of the first helix of the linker was positioned in close proximity to the $\mathrm{C}$ terminus of the M1 helix, as they are separated by at most three residues; (2) the second helix was angled so that its C-terminal end was not too far from the N-terminal end of the P1 pore helix; (3) N53 was mutated to Cys, and a disulphide bridge was modelled between the substituted Cys residues; and (4) secondary structure restraints were imposed to retain the two predicted helices. Once the initial model was created, the Cys residues were mutated back to Asn.

The extended loop between the selectivity filter of P2 and M4 is eight residues longer in TASK-1 than in KcsA, and thus, this was modelled by using the webserver loop build-up and optimization (LOBO) [52]. The first of the eight solutions generated was chosen as it agreed most closely with the secondary structure prediction. There are no templates with structural equivalence for the C-terminal region of the TASK-1 sequence, and thus, this region was omitted from the models. The positions of ions and water molecules were modelled from the KcsA structure. The mutants of TASK-1 were modelled and analysed using the molecular graphics program Pymol [14]. 
Table 1 Relative permeabilities to $\mathrm{Rb}^{+}$and $\mathrm{Na}^{+}$of mutants of the selectivity filters of $\mathrm{P} 1$ and $\mathrm{P} 2$

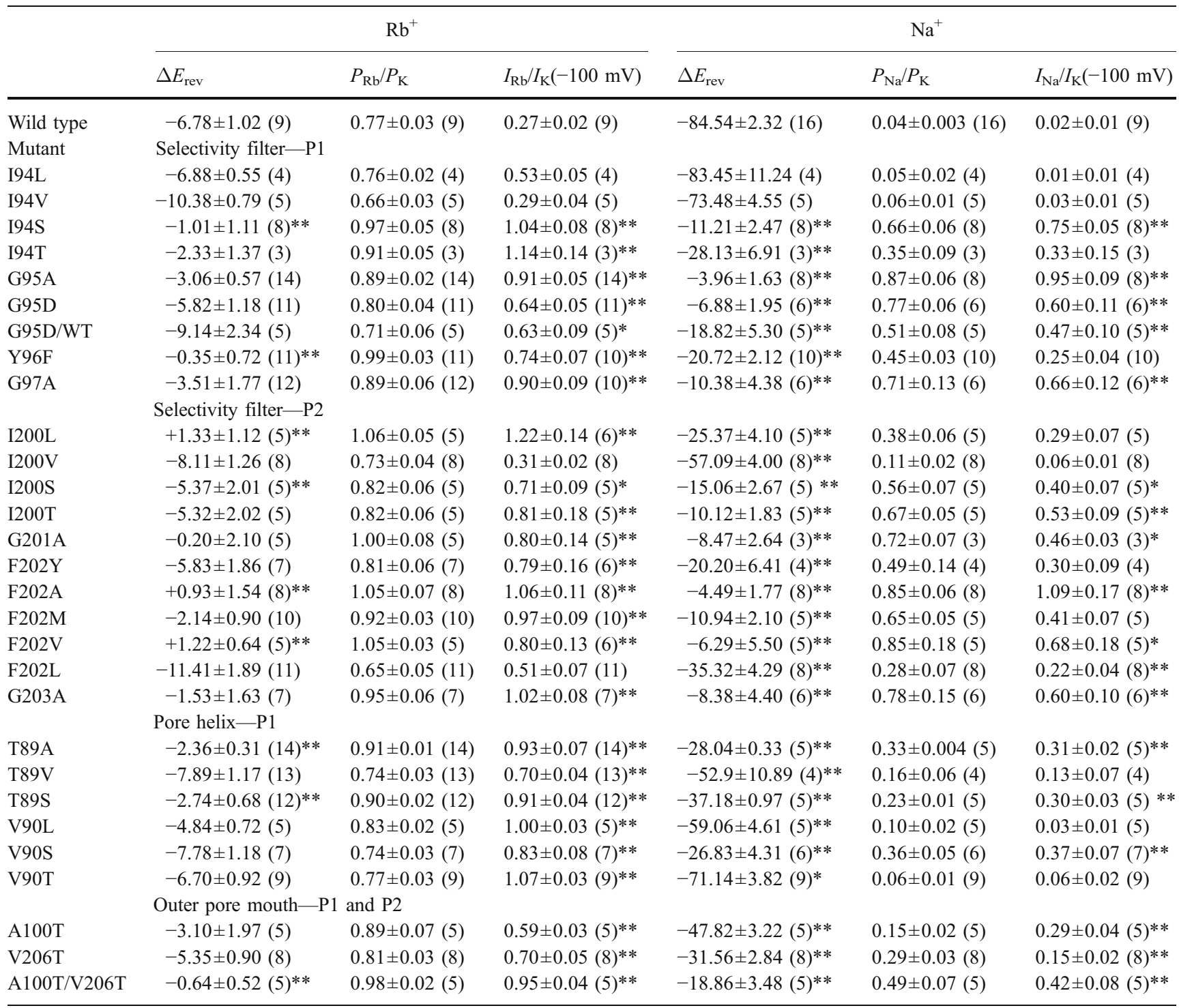

The experimentally measured quantities were compared statistically using analysis of variance; $*<0.05$; ** $P<0.01$. Mutants G95E, G95E/WT, Y96L, Y96M and Y96V were also examined but failed to generate functional channels.

\section{Results}

Evaluation of the TASK-1 comparative model

A structural model of TASK-1 has been constructed of the region from Met1, at the $\mathrm{N}$ terminus, through to Arg257, in the M4 transmembrane helix. In addition to describing the pore domain of the TASK-1 channel, which is already relatively well represented by analogy with the available $\mathrm{K}^{+}$ channel crystal structures, the model hypothesises for the first time the structure of the domain that links the M1 transmembrane helix to the pore helix in the P1 segment and provides a picture of the $\alpha$-helical structure and orientation of the M2-M3 linker that connects the P1 and
P2 segments. The structure is shown schematically in Supplementary Fig. 1b. The differences in the structures of the P1 and P2 segments of the TASK-1 model are shown in Fig. 1. The structure is in its closed conformation, but serves to illustrate the residues contributing the pore regions, which are the subject of this study.

The residues in the region comprising the pore helix through to the inner transmembrane helix share a $40 \%$ similarity in $\mathrm{P} 1$ and $37 \%$ in $\mathrm{P} 2$ with the template structure, KcsA. In addition, among the residues in and around the selectivity filter, those that were mutated in this study share a $67 \%$ similarity in $\mathrm{P} 1$ and $50 \%$ in $\mathrm{P} 2$. This level of homology is high enough to create a relatively accurate model of the TASK-1 channel, which is stable in 
Table 2 Response to acidification of TASK-1 mutants

\begin{tabular}{|c|c|c|c|c|}
\hline Mutant & $\mathrm{p} K_{\mathrm{a}}(-40)$ & Acid sensitive current fraction & $\mathrm{p} K_{\mathrm{a}}(+40)$ & Acid sensitive current fraction \\
\hline Wild type & $6.66 \pm 0.05(13)$ & Set to 1 & $6.57 \pm 0.06(13)$ & Set to 1 \\
\hline \multicolumn{5}{|c|}{ Selectivity filter $-\mathrm{P} 1$} \\
\hline I94S & $7.34 \pm 0.60$ & $0.17 \pm 0.08$ & $7.48 \pm 0.44$ & $0.26 \pm 0.08$ \\
\hline I94T & $7.62 \pm 0.63(4)^{*}$ & $0.47 \pm 0.10$ & $6.34 \pm 0.53$ & $0.23 \pm 0.05$ \\
\hline$I 94 L$ & $7.06 \pm 0.12$ & 1 & $6.83 \pm 0.09$ & 1 \\
\hline$I 94 \mathrm{~V}$ & $6.19 \pm 0.21$ & 1 & $6.18 \pm 0.19$ & 1 \\
\hline G95A & Assumed as WT & $0.16 \pm 0.07(9)$ & Assumed as WT & $0.23 \pm 0.07(9)$ \\
\hline Y96F & $8.48 \pm 0.09(8)^{* *}$ & $0.77 \pm 0.02$ & $8.47 \pm 0.07(8)^{* *}$ & $0.81 \pm 0.03$ \\
\hline G97A & $7.60 \pm 0.21(5)^{* *}$ & $0.67 \pm 0.05$ & $8.30 \pm 0.21(5)^{* *}$ & $0.83 \pm 0.04$ \\
\hline \multicolumn{5}{|c|}{ Selectivity filter-P2 } \\
\hline I $200 \mathrm{~S}$ & Not fitted & & $6.86 \pm 0.07(3)$ & $0.27 \pm 0.04$ \\
\hline $\mathrm{I} 200 \mathrm{~T}$ & $7.54 \pm 0.39(5)^{* *}$ & $0.86 \pm 0.04$ & $7.21 \pm 0.53(5)$ & $0.62 \pm 0.03$ \\
\hline $\mathrm{I} 200 \mathrm{~L}$ & $7.38 \pm 0.15$ & $0.77 \pm 0.03$ & $7.52 \pm 0.09(4)^{*}$ & $0.71 \pm 0.04$ \\
\hline$I 200 \mathrm{~V}$ & $6.50 \pm 0.27(5)$ & $0.52 \pm 0.02$ & $7.35 \pm 0.35(6)^{*}$ & $0.58 \pm 0.17$ \\
\hline F202Y & $7.73 \pm 0.33(4)^{* *}$ & $0.18 \pm 0.05$ & $7.74 \pm 0.55(3)^{* *}$ & $0.30 \pm 0.03$ \\
\hline \multicolumn{5}{|c|}{ Outer pore mouth $-\mathrm{P} 1$ and $\mathrm{P} 2$} \\
\hline$A 100 T$ & Assumed as WT & $0.20 \pm 0.08(8)$ & Assumed as WT & $0.17 \pm 0.08$ \\
\hline V206T & $8.12 \pm 0.13(5)^{* *}$ & $0.86 \pm 0.02$ & $8.25 \pm 0.11(5)^{* *}$ & $0.88 \pm 0.03$ \\
\hline \multicolumn{5}{|c|}{ Pore helix-P1 } \\
\hline T89S & $6.97 \pm 0.08$ & $0.89 \pm 0.09$ & $7.02 \pm 0.15(5)$ & $0.83 \pm 0.06$ \\
\hline T89A & $8.21 \pm 0.09(6)^{* *}$ & $0.76 \pm 0.04$ & $8.19 \pm 0.08(6)^{* *}$ & $0.79 \pm 0.03$ \\
\hline $\mathrm{T} 89 \mathrm{~V}$ & $8.27 \pm 0.16(6)^{* *}$ & $0.86 \pm 0.04$ & $8.46 \pm 0.16(6)^{* *}$ & $0.86 \pm 0.03$ \\
\hline$V 90 L$ & $7.55 \pm 0.07(6)^{* *}$ & 1 & $7.71 \pm 0.09(6)^{* *}$ & $0.93 \pm 0.02$ \\
\hline V90T & $7.18 \pm 0.05$ (4) & 1 & $7.59 \pm 0.16(4)^{*}$ & $0.86 \pm 0.01$ \\
\hline
\end{tabular}

The results are fitted to Eq. 2 of the text, that is to: $y=a \cdot\left\{1+\frac{\left[H^{+}\right]_{o}}{K_{a}}\right\}^{-1}+b$, where $y$ is the fractional current. The acid sensitive fraction is computed as $a /(a+b)$. $\mathrm{p} K_{a}=-\log _{10} K_{a}$. We have used analysis of variance, with Dunnett's multiple comparisons test, to compare values for $\mathrm{p} K_{a}$ obtained from the best fit to the experimental results with those obtained for wild type. ${ }^{*}$ and ${ }^{* *}$ denote significant differences with $P<0.05$ and $<0.01$, respectively. Mutants shown in italics have $P_{\mathrm{Na}} / P_{\mathrm{K}} \leq 0.2$.

subsequent molecular dynamics simulations. There are several differences between the sequences of the P-regions of P1 (Fig. 1c) and P2 (Fig. 1d). These differences are accentuated structurally with the aromatic of the $\mathrm{G}(\mathrm{Y} / \mathrm{F}) \mathrm{G}$ motif and are reflected in the residues surrounding the filter, making the region behind the selectivity filter of P1 relatively more hydrophilic than that behind the selectivity filter of P2. In the region of interest, a $58 \%$ sequence identity is shared between the P1 and P2 segments of TASK-1.

\section{Permeability of TASK- 1 to $\mathrm{Rb}^{+}$and $\mathrm{Na}^{+}$}

Figure 2 shows records and current-voltage relationships for wild-type TASK-1 in the presence of $70 \mathrm{mM}\left[\mathrm{K}^{+}\right]_{\mathrm{o}}$, $\left[\mathrm{Rb}^{+}\right]_{\mathrm{o}}$ and $\left[\mathrm{Na}^{+}\right]_{\mathrm{o}}$. As described previously $[16,28]$, current-voltage relations show weak outward rectification in $\mathrm{K}^{+}$solutions. This rectification is close to, but not identical with, that expected from constant field theory, with a higher concentration of $\mathrm{K}^{+}$internally. Outward currents are larger than expected from these considerations (Fig. 2c), as channels show a weakly voltage-dependent gating (see below), which occurs over a wide range of voltages [32].

As we have previously shown [55], $\mathrm{Rb}^{+}$readily permeates wild-type TASK-1 channels, relative permeability being measured using Eq. 1. Under hyperpolarisation, $\mathrm{Rb}^{+}$currents are, however, smaller than $\mathrm{K}^{+}$currents, and $\mathrm{Rb}^{+}$in the external solution impedes $\mathrm{K}^{+}$efflux at depolarising voltages up to $+80 \mathrm{mV}$ (Fig. $2 \mathrm{~b}, \mathrm{c}$ ), suggesting that $\mathrm{Rb}^{+}$acts as a blocking cation (see also [39]). As previously described by ourselves [55] and others [32], the relative permeability to $\mathrm{Na}^{+}$is low (Table 1; Fig. 2d); as is the case for other $\mathrm{K}^{+}$channels, $\mathrm{Na}^{+}$may be considered essentially impermeant.

Mutations of the pore regions - mutations of the selectivity filter in P1 and P2

We have made mutations of many residues of the selectivity filter and pore helix (which helps stabilise the selectivity filter) of both the P1 and P2 domains of TASK-1. The effect of these mutations on the relative permeabilities of $\mathrm{K}^{+}, \mathrm{Rb}^{+}$ and $\mathrm{Na}^{+}$is documented in Table 1 . 
Fig. 1 Homology model of the TASK-1 Channel. a The P1 segment of the TASK-1 homology model. b The P2 segment of the TASK-1 homology model. The region shown in (c) and (d) is highlighted by a dashed box. c The residues within the pore helices and selectivity filter of P1. d The residues within the pore helices and selectivity filter of $\mathrm{P} 2$ a
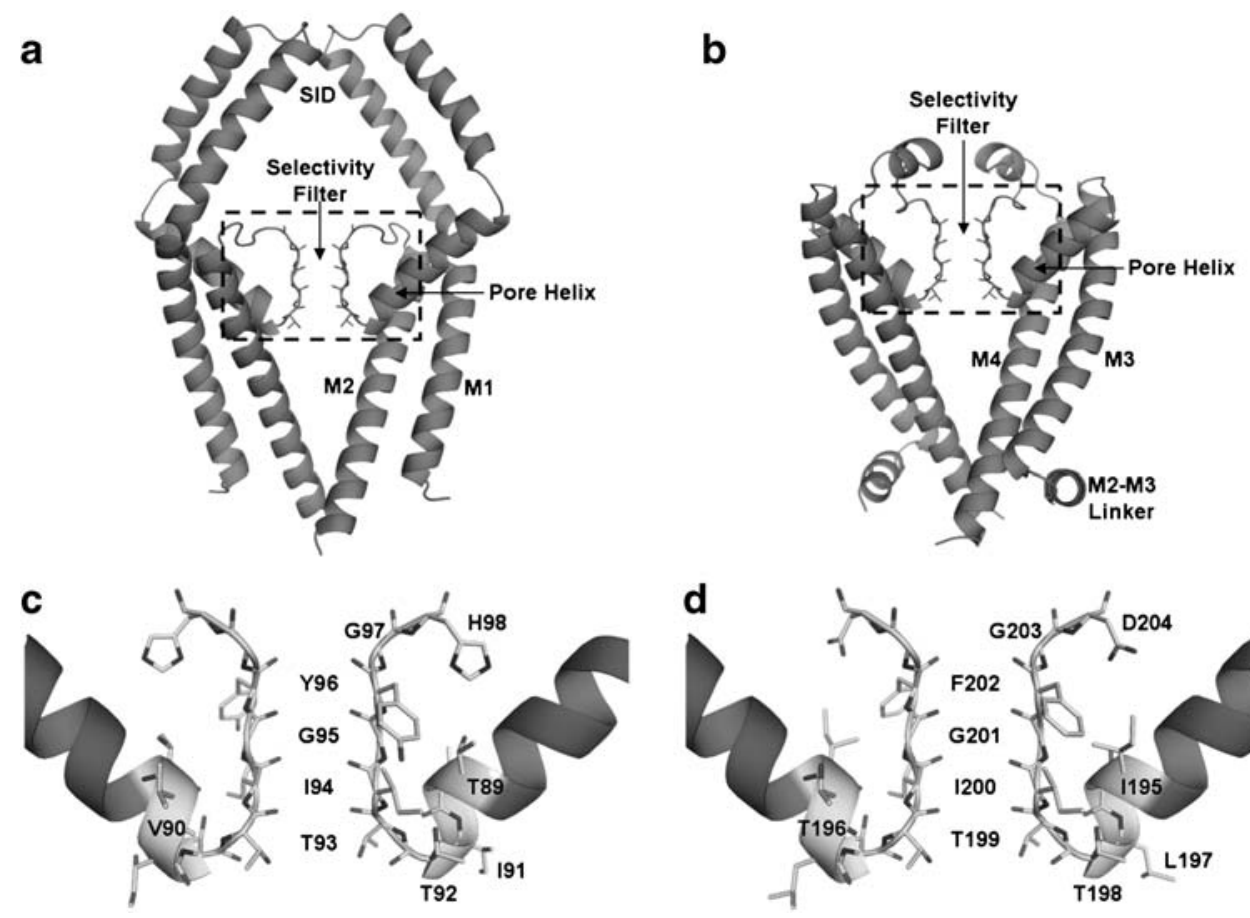

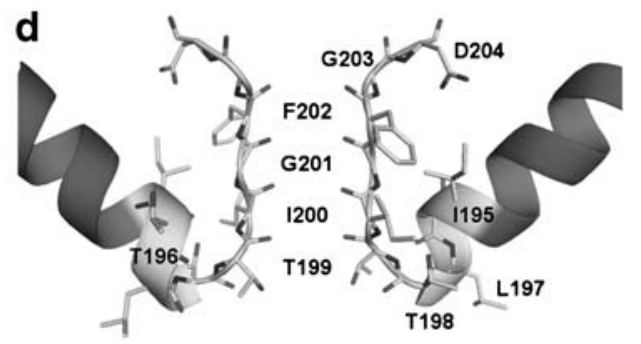

GYG and GFG triplets: replacement of glycines

Mutations of the triplet of residues GYG in P1 and GFG in P2 all alter selectivity (Table 1: Fig. 3). It was anticipated that replacement of Gly residues would abolish selectivity, and this is indeed the result found. Channels where either G95 or G97 is replaced by Ala fail to distinguish $\mathrm{K}^{+}$from $\mathrm{Rb}^{+}$or $\mathrm{Na}^{+}$(Table 1 and Fig. 3). Similar results were obtained by replacing the equivalent residues in P2, G201 and 203, in turn by Ala (Table 1).
Fig. 2 Ionic selectivity of wildtype channels. Current records for wild type in $70 \mathrm{mM}\left[\mathrm{K}^{+}\right]_{\mathrm{o}}$ (a) and in $70 \mathrm{mM}\left[\mathrm{Rb}^{+}\right]_{\text {o }}$ solutions $(\mathbf{b})$.

The membrane was held at $-20 \mathrm{mV}$ and stepped in $10 \mathrm{mV}$ increments to between -100 and $+100 \mathrm{mV}$. The horizontal arrows show the zero current level.

c Current voltage relations measured in a Xenopus oocyte expressing wild-type TASK-1 in solutions containing $70 \mathrm{mM}$ $\left[\mathrm{K}^{+}\right]_{\mathrm{o}}$ ( filled circle) and $70 \mathrm{mM}$ $\left[\mathrm{Rb}^{+}\right]_{\mathrm{o}}$ (open circle). $\mathrm{Rb}^{+}$reduced outward $\mathrm{K}^{+}$current under depolarisations up to $+80 \mathrm{mV}$. The dashed grey line is computed by fitting the hyperpolarising element of the current voltage relation in $\mathrm{K}^{+}$solution with the constant field equation $I_{K}=P_{K} \frac{\mathrm{VF}^{2}}{\mathrm{RT}}\left\{\frac{\left[K^{+}\right]_{0} \cdot \exp (\mathrm{VF} / \mathrm{RT})-\left[K^{+}\right]_{i}}{\exp (\mathrm{VF} / \mathrm{RT})-1}\right\}$ and extrapolating over the depolarising region. Outward currents are larger than predicted owing to a voltage- and time-dependent increase in current under depolarisation. d Current voltage relations in $70 \mathrm{mM}\left[\mathrm{K}^{+}\right]_{\mathrm{o}}$ ( filled circle) and $70 \mathrm{mM}\left[\mathrm{Na}^{+}\right]_{\mathrm{o}}$ (triangle)
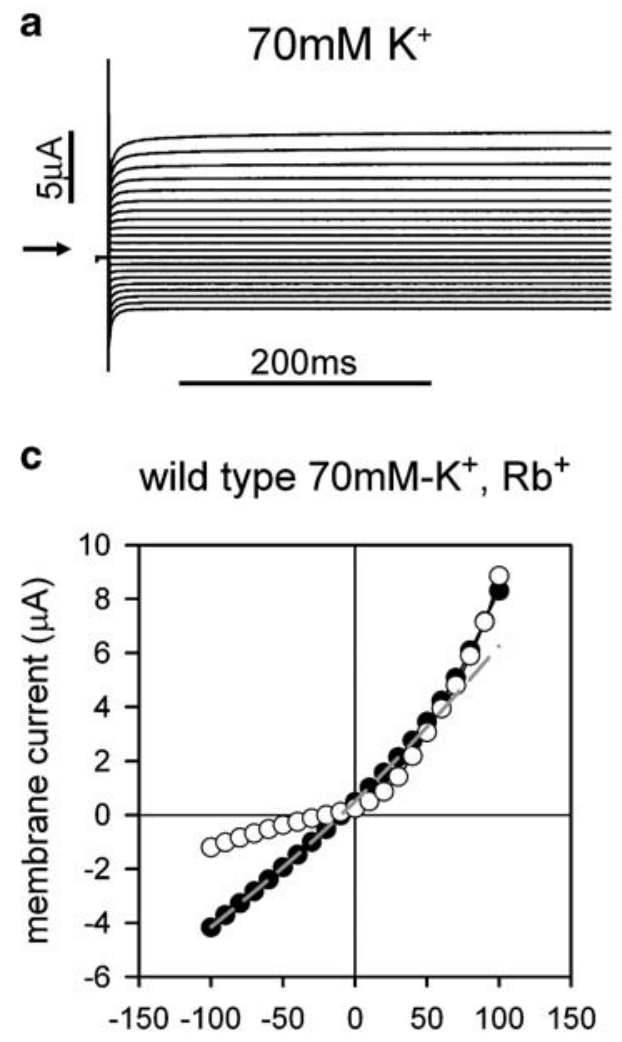

membrane potential $(\mathrm{mV})$ b

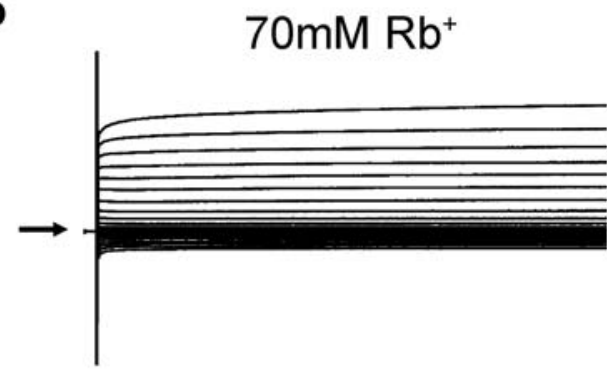

d

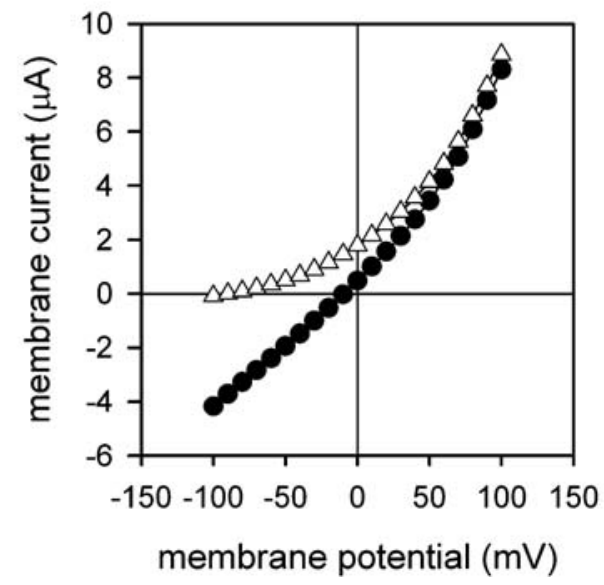


Fig. 3 Mutation of the glycine residues of the $\mathrm{GY}(\mathrm{F}) \mathrm{G}$ triplet and ionic selectivity. Typical current voltage relations from individual oocytes expressing the TASK-1 mutants: a G95A in $70 \mathrm{mM}\left[\mathrm{K}^{+}\right]_{\mathrm{o}}$ ( filled circle) and in $70 \mathrm{mM}\left[\mathrm{Rb}^{+}\right]_{\mathrm{o}}$ (open circle); b G97A in $70 \mathrm{mM}\left[\mathrm{K}^{+}\right]_{\mathrm{o}}$ ( filled circle) and in $70 \mathrm{mM}\left[\mathrm{Rb}^{+}\right]_{\text {o }}$ (open circle); c G95A in70 mM $\left[\mathrm{K}^{+}\right]_{\mathrm{o}}$ ( filled circle) and in $70 \mathrm{mM}\left[\mathrm{Na}^{+}\right]_{\mathrm{o}}$ (open circle) and d G97A in $70 \mathrm{mM}\left[\mathrm{K}^{+}\right]_{\mathrm{o}}$ (filled circle) and in $70 \mathrm{mM}\left[\mathrm{Na}^{+}\right]_{\mathrm{o}}$ (open circle) showing resultant loss of selectivity a

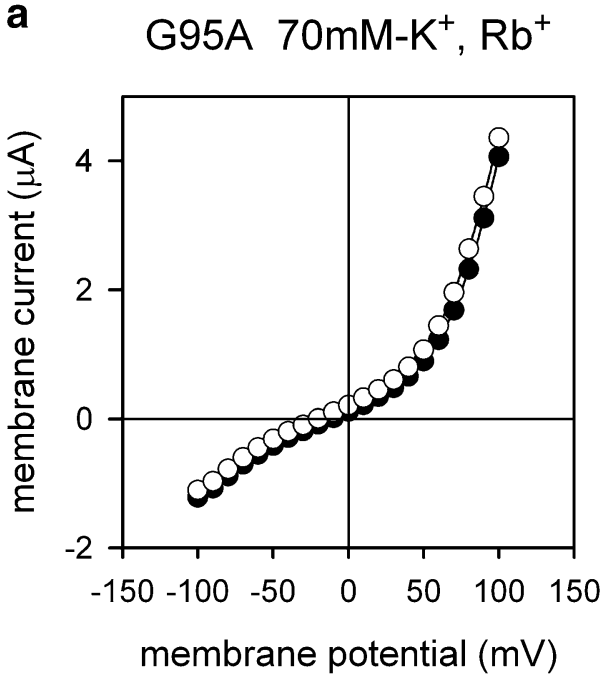

b

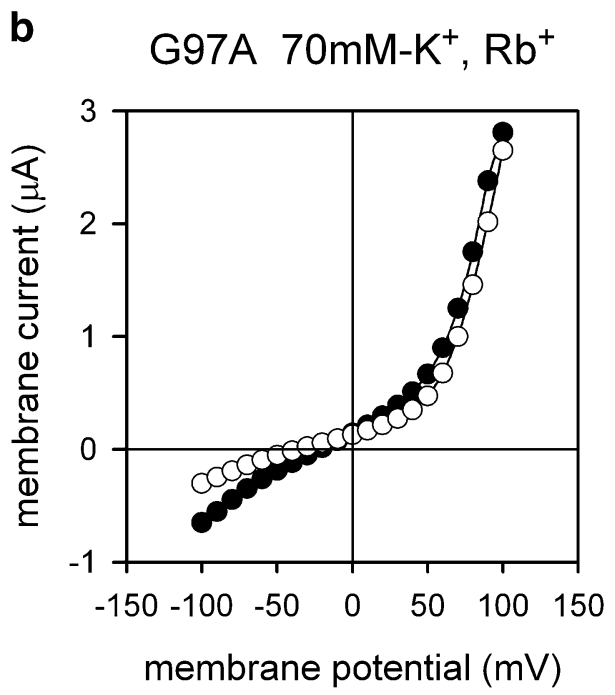

C

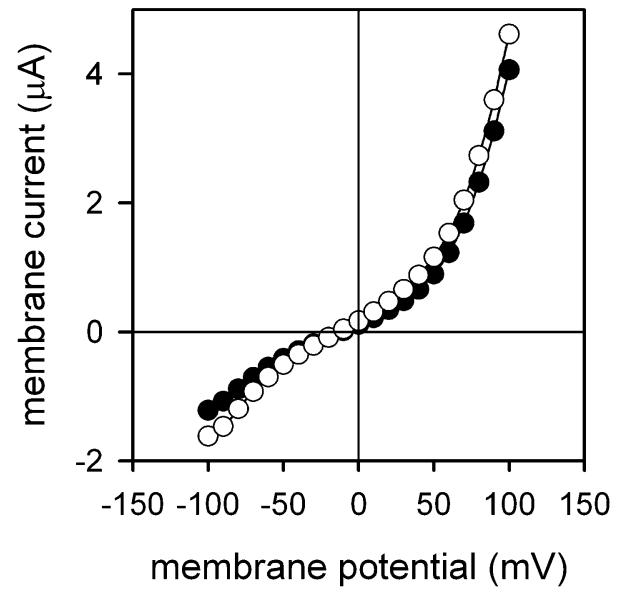

d

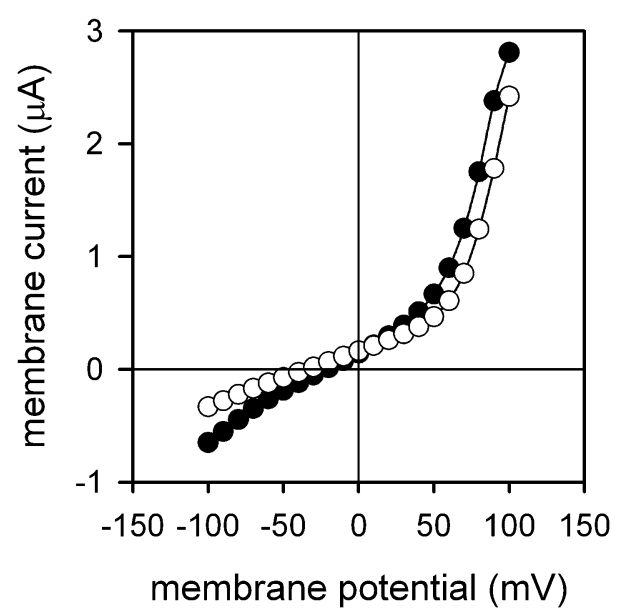

Table 1 also gives the results of replacement of G95 by glutamate or aspartate. Others have already identified G95E as a loss of function mutation [22, 27, 42], acting as a dominant negative when co-expressed with other TASK subunits. The mutation is found in TASK-5 of some humans, owing to single nucleotide polymorphism at this point in the sequence $[22,25]$. We were unable to measure currents in oocytes injected with the cRNA of G95E or of a concatameric dimer (G95E/WT) where only one subunit of the dimeric structure has the mutation.

However, the mutant G95D produced functional, nonselective channels (Table 1), as did the concatameric channel G95D/WT. There was no significant difference between G95D and the G95D/WT concatamer in the quantities used to measure selectivity (Table $1 ; P>0.05$ in all cases). The replacement of a single Gly95 by Asp in the concatameric dimer appears as damaging to selectivity as is replacement of the residue in both subunits.
GYG and GFG triplets: replacement of aromatic residues

The effects of alterations of the central residue of the GYG or GFG triplet are more striking in TASK-1 than in Kv or in $\mathrm{Kir}$, as even conservative substitutions abolish selectivity. Among the residues we used to replace Y96, only Phe produced functional channels, and we were unable to measure currents when Y96 was substituted by Leu, Met or Val. Y96F channels were non-selective (Table 1; Fig. 4a, b). Although the effects of the substitution of Y 96 by F are less substantial than those caused by replacement of G95 and G97, the loss of selectivity is much greater than that seen in either Shaker Kv channels or in Kir [20, 47].

However, it was possible to replace F202 with one of a number of alternatives (Table 1). All replacements affected selectivity including F202Y (Table 1, Fig. 4c,d). This result contrasts with that of Hajdú et al. [19], who argued for retention of selectivity with the change $\mathrm{F}$ to $\mathrm{Y}$. In fact, in 

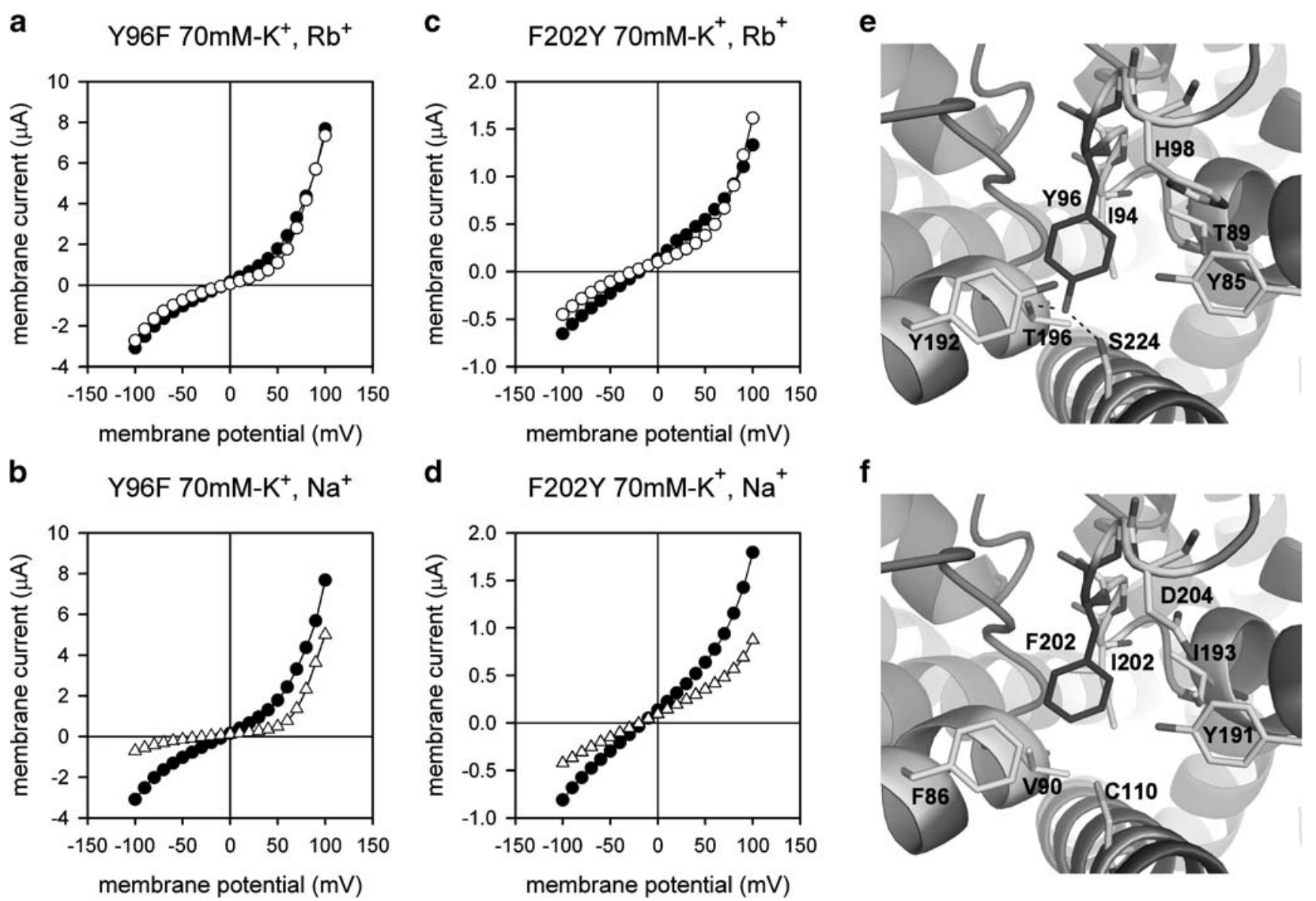

Fig. 4 Mutation of Y96 and F202 of the GY(F)G triplet and ionic selectivity. Typical current voltage relations from individual oocytes expressing the TASK-1 mutants: a Y96F in $70 \mathrm{mM}\left[\mathrm{K}^{+}\right]_{\mathrm{o}}$ ( filled circle) and in $70 \mathrm{mM}\left[\mathrm{Rb}^{+}\right]_{\mathrm{o}}$ (open circle); b Y96F in $70 \mathrm{mM}\left[\mathrm{K}^{+}\right]_{\mathrm{o}}$ (filled circle) and in $70 \mathrm{mM}\left[\mathrm{Na}^{+}\right]_{\mathrm{o}}$ (triangle); c F202Y in $70 \mathrm{mM}$ $\left[\mathrm{K}^{+}\right]_{\mathrm{o}}$ ( filled circle) and in $70 \mathrm{mM}\left[\mathrm{Rb}^{+}\right]_{\mathrm{o}}$ (open circle); $\mathbf{d}$ F202Y in $70 \mathrm{mM}\left[\mathrm{K}^{+}\right]_{\mathrm{o}}$ ( filled circle) and in $70 \mathrm{mM}\left[\mathrm{Na}^{+}\right]_{\mathrm{o}}$ (triangle); potential

interactions behind the selectivity filter suggested by our modelling studies (e) Y96 (P1) may form hydrogen bonds with T196 and S224 (depicted by dashed lines). (f) F202 (P2) is in a more hydrophobic environment than the equivalent residue in P1 (Y96), consistent with the loss of the hydroxyl. F86, V90, C110, Y191, I195, I200 and D204 surround F202

our experiments, mutants F202A and F202V were, alongside G95A, the least selective of any mutants we have made (Table 1). These differences between $\mathrm{P} 1$ and $\mathrm{P} 2$ and between TASK-1 and other $\mathrm{K}^{+}$channels are likely to reflect different residues stabilising the selectivity filter.

In our model (Fig. 4e,f), Y96 is predicted to point into an environment that is more hydrophilic than that seen by F202 at the back of P2. The model predicts that Y96 can form hydrogen bonds with T196 in the P2 pore helix and S224 in M4 and that other hydrophilic residues, including Y85, T89, and Y192, may contribute to the hydrogen bonding network surrounding Y96. In terms of the model, reduced selectivity is explained in terms of the loss of these bonds in $\mathrm{Y} 96 \mathrm{~F}$ and the resultant destabilising of the pore structure. Our model does not show the contact between Y96 and D204 that others have suggested [7]. F202 is predicted to lie in a more hydrophobic environment, with nearby residues including F86 and V90 in the pore helix of P1 and I195 in the pore helix of P2. However, in F202Y, hydrogen bonding may occur with Y191 in the pore helix of P2, the lack of selectivity being associated with the altered structure.

GY(F)G and effects of mutation on voltage dependent gating

Figure 5a shows that wild-type currents increase with time under depolarisation. The process was little affected by omission of both $\mathrm{Ca}^{2+}$ and $\mathrm{Mg}^{2+}$ from our experimental (extracellular) solutions (data not shown) and is then not due to ionic blockage of channels by these divalent cations. Lopes et al. [32] have already described this gating process and shown it to be dependent on the concentration of $\mathrm{K}^{+}$in the extracellular solution and more prominent in physiological $\left[\mathrm{K}^{+}\right]_{\mathrm{o}}$. The observation that, at a given voltage, channels are more likely to be shut in low $\left[\mathrm{K}^{+}\right]_{\text {o }}$ raises the possibility that voltage gating is associated with conformation changes in the filter. 
a

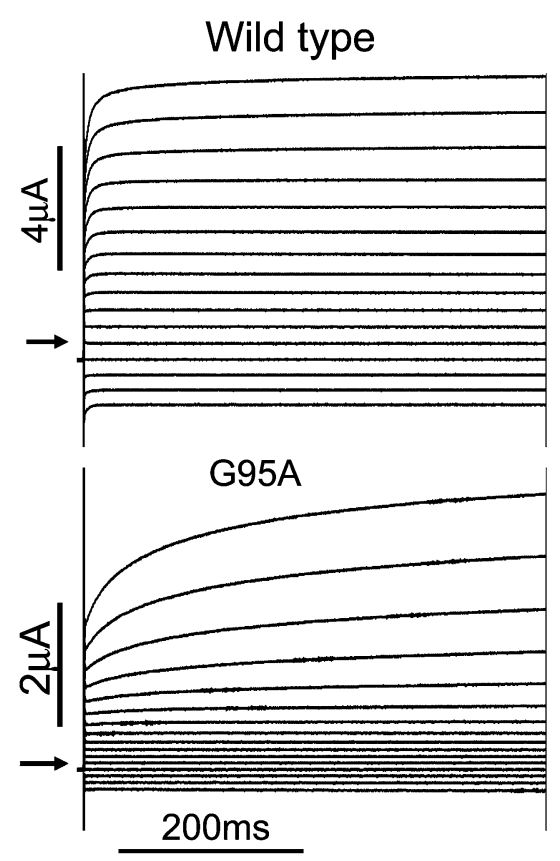

b
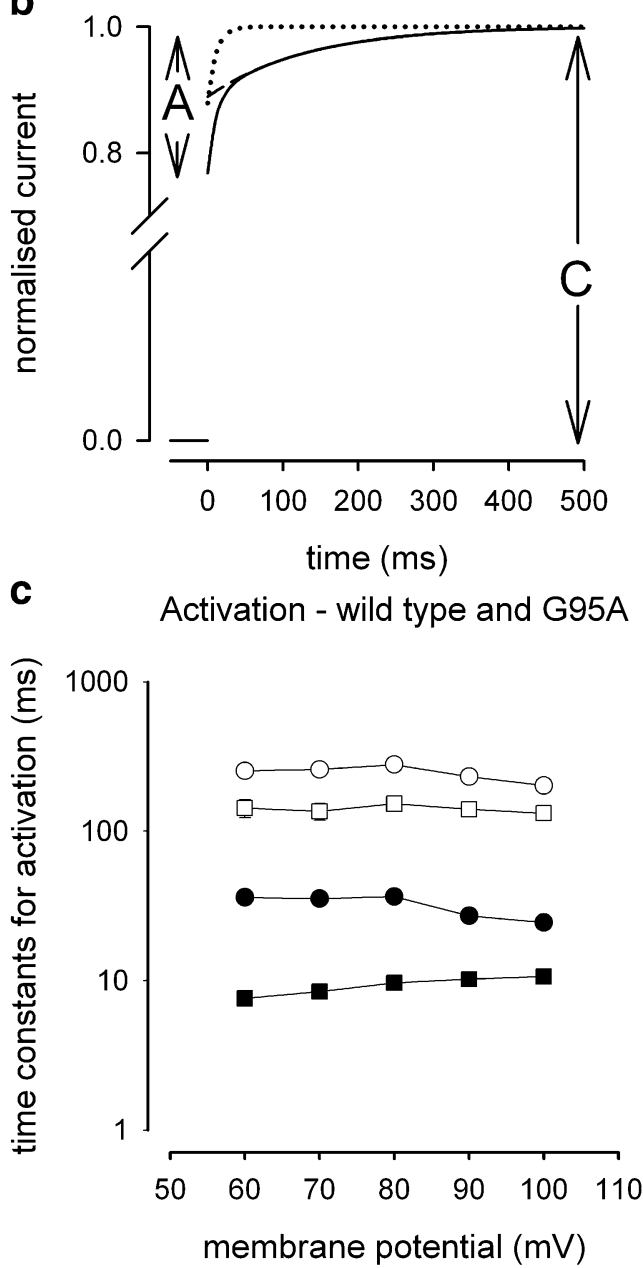

the text, the fraction of the current activated by the depolarisation is computed by the quantity $A / C$ as illustrated. The fast and slow components are indicated as the dotted and the dashed lines, respectively. The mean values from the fits to wild-type currents were used to compute the diagram. c Plot of activation time constants $\tau_{1}$ (filled square for wild type and filled circle for G95A) and $\tau_{2}$ (open square for wild type and open circle for G95A) against voltage obtained by fitting currents as in (b). Error bars indicate \pm SEM. Both elements of activation are significantly slowed in the mutant channel

current represents $0.23 \pm 0.02 \quad(n=16)$ of the steady state current. In $\mathrm{G} 95 \mathrm{~A}$, the fraction is increased significantly $(P<0.01)$ to $0.41 \pm 0.03(n=9)$.

The time constants for this increase in current are illustrated in Fig. 5c. Lopes et al. [32] have shown that these time constants are only weakly dependent on voltage, describing those for activation as changing $e$-fold per $250 \mathrm{mV}$, those for deactivation $e$-fold per $500 \mathrm{mV}$. This weak voltage dependence makes full analysis of the gating process difficult, and we have not attempted for the present to quantify the gating charge. However, the time constants for activation are increased significantly in G95A over their values in wild type. Further, the slow component of activation is increased in this mutant. In G95A, it represents several $100 \mathrm{~ms}$. In wild type at $+100 \mathrm{mV}$, this increase in 
$0.30 \pm 0.03$ of the steady state current, whereas in wild type, it represents only $0.11 \pm 0.02$ of steady state current, a difference that is significant $(P<0.01 ; n=8)$. Similar results were found with other mutants of the GY(F)G triplet. The mutant G95D, which introduces a charged residue into P1 and might be expected to introduce an altered response to voltage did not produce results different from those with G95A (data not shown).

\section{Response to acidification of mutants of GY(F)G}

TASK-1 is sensitive to extracellular acidification, and several authors have described the $\mathrm{pH}$-sensitivity of wild type TASK-1 channels and its weak voltage dependence [1, 16, 32, 38]. Fitting Eq. 2 to the relationship between wildtype current and $\mathrm{pH}_{\mathrm{o}}$ gave values for $p K_{a}$ of $6.66 \pm 0.05$ and $6.57 \pm 0.06$ (13) at membrane potentials of -40 and $+40 \mathrm{mV}$, respectively (Fig. 6a,b). Several authors have described how mutation of $\mathrm{H} 98$ at the mouth of the pore reduced acid sensitivity [1, 26, 44, 33, 38].

However, as Fig. 6a,b shows, currents through the mutant G95A were also little altered by acidification. In this mutant, currents at $\mathrm{pH} 6$ and $+40 \mathrm{mV}$ were still $0.85 \pm$ 0.05 of their amplitude at $\mathrm{pH} 8.5$ indicating that little inhibition occurred. In wild type at $\mathrm{pH} 6$, currents were $0.24 \pm 0.01$ (12) of their amplitude at $\mathrm{pH} 8.5$ (Fig. 6a).

Replacement of Tyr96 by Phe also alters pH sensitivity. In this instance (Fig. $6 \mathrm{c}$ ), considerable $\mathrm{K}^{+}$current persists at low $\mathrm{pH}_{\mathrm{o}}$, but currents increase under alkalinisation. We have previously described a similar response for D204H and D204N mutant channels [55]. Mutation of Y96 (and D204) thus results in channels that are insensitive to $\mathrm{pH}$ changes around physiological $\mathrm{pH}$ but are further activated upon alkalinisation, a property reminiscent of, but not identical with, the response of alkali-sensitive tandem-pore channels such as TASK-2 and other members of the TALK
Fig. 6 Response to acidification of wild-type TASK-1 and of selectivity filter mutants. a Relationship between the membrane current, normalised to that at $\mathrm{pH}_{\mathrm{o}}=8.5$, (ordinate) and $\mathrm{pH}_{\mathrm{o}}$ (abscissa) for wild type (filled circle) and G95A (filled triangle), measured at $+40 \mathrm{mV}$. The points give the mean \pm SEM in each case. The lines are drawn using Eq. 2 of the text, that is to: $y=a \cdot\left\{1+\frac{\left[H^{+}\right]_{o}}{K_{a}}\right\}^{-1}+b$. In both cases, $\mathrm{p} K a=6.54$ (best fit to the mean results for wild type). For G95A, $a=0.14$, $b=0.86$. b Relationship between membrane current and $\mathrm{pHo}$, as in (a) but measured at $-40 \mathrm{mV}$ for wild type (open triangle) and G95A (open circle). Lines are drawn using Eq. 2 with $\mathrm{p} K_{\mathrm{a}}=6.64$; for G95A, $a=0.19$, $b=0.81$. c Similar relationships for $\mathrm{Y} 96 \mathrm{~F}$ at $-40 \mathrm{mV}$ (open triangle). The solid line gives $\mathrm{p} K_{\mathrm{a}}=8.46, a=1.23, b=0.35$ for the fit to $-40 \mathrm{mV}$. d Similar relationships for F202Y at $-40 \mathrm{mV}$ (open circle). The solid line gives $\mathrm{p} K_{\mathrm{a}}=7.36, a=0.18$, $b=0.82$ for the fit to $-40 \mathrm{mV}$. For parts (c) and (d), the dashed line gives the best fit to wild type at $-40 \mathrm{mV}$ (as in b) a

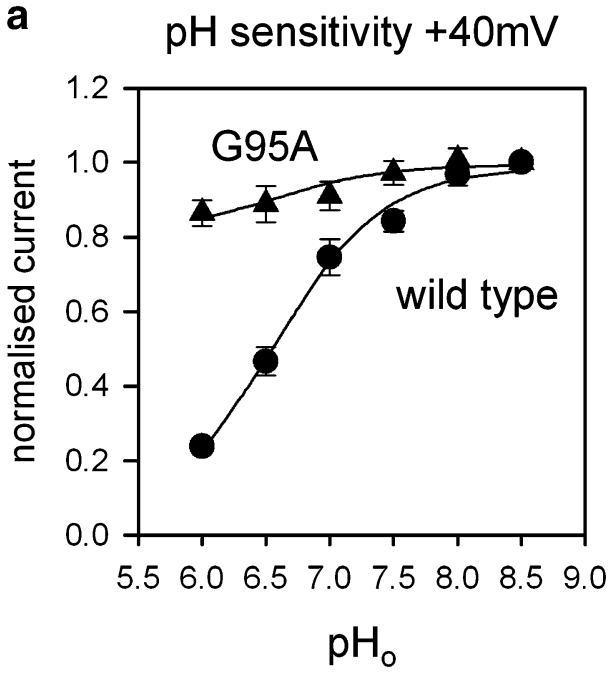

b

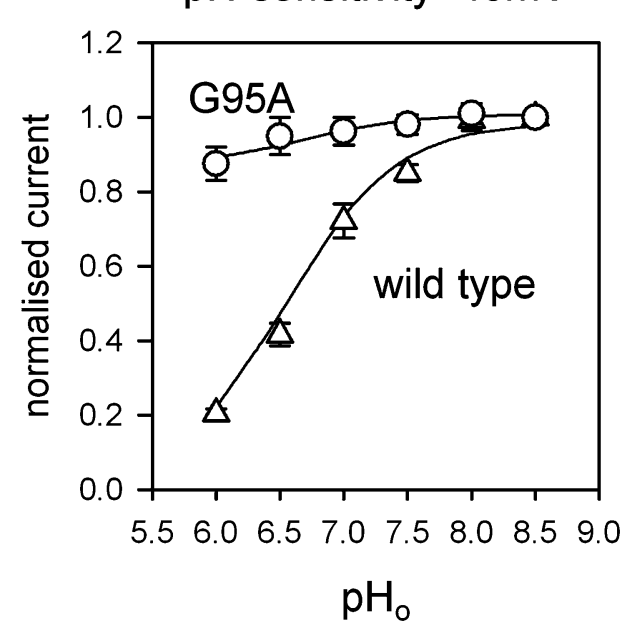

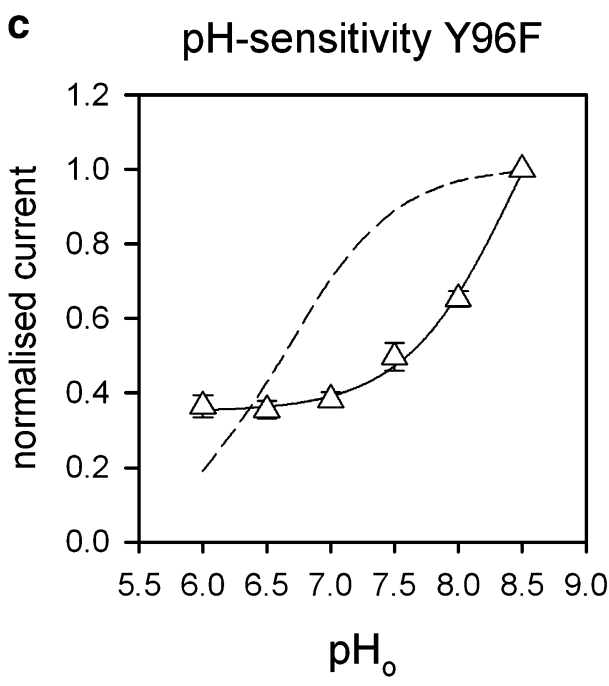

d

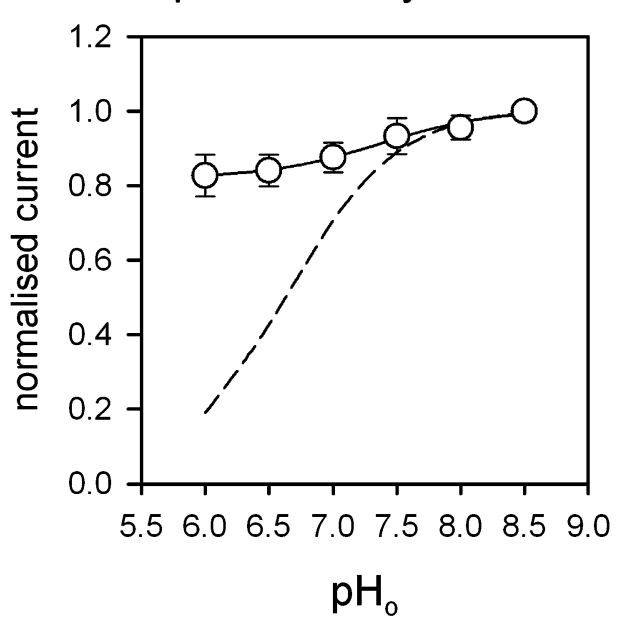


subfamily [13, 17, 45]. Chapman et al. [7] have proposed an interaction between residues Y96 and D204 in TASK-1, and a similarity in response of these mutants to acidification (Y96F here, D204N in [55]) might be taken as further evidence for such an interaction. However, other mutants have similar properties. The mutant G97A responds to $\Delta \mathrm{pH}_{\mathrm{o}}$ in a similar way to that shown by Y96F (Table 2), its properties contrasting with those of G95A and I94S, T (see below), where the response to acidification is effectively abolished. The mutant F202Y shows little reduction in current in acid conditions (Table 2; Fig. 6d).

Thus, mutants of the selectivity filter have radically altered responses to changes of extracellular $\mathrm{pH}\left(\Delta \mathrm{pH}_{\mathrm{o}}\right)$. The simplest explanation is that the response to acidification involves gating at the pore and that disrupting the pore structure disrupts these gating movements.

Isoleucine 94 and 200: effects on ionic selectivity We now test further the hypotheses that both voltage dependence and $\mathrm{pH}$ sensitivity involve the selectivity filter using mutants of I94 and I200 (equivalent residues in the P1 and P2 domains, respectively; Fig. 1). In Kv [51] and Kir channels [40], effects on selectivity of the mutation of the equivalent residue were correlated with the hydrophobicity of the side chain of the substituted residue. A similar correlation was found in TASK-1 (Table 1; Fig. 7), and we describe first the ionic selectivity of these mutants.

We found that replacement of I94 (P1) with the hydrophobic residues Leu and Val had relatively little effect on selectivity against $\mathrm{Na}^{+}$in particular (Table 1, Fig. 7), but replacement by the hydrophilic residues Ser or Thr made channels non-selective (Table 1; Fig. 7c,d). The loss of selectivity against $\mathrm{Na}^{+}$was the more complete in I94S perhaps because the bulkier side chain of Thr helps maintain a structure that is closer to that found in wild type. For I200 (P2; Table 1), selectivity is altered little in I200V, but is lost in I200S and I200T, a result that parallels that a

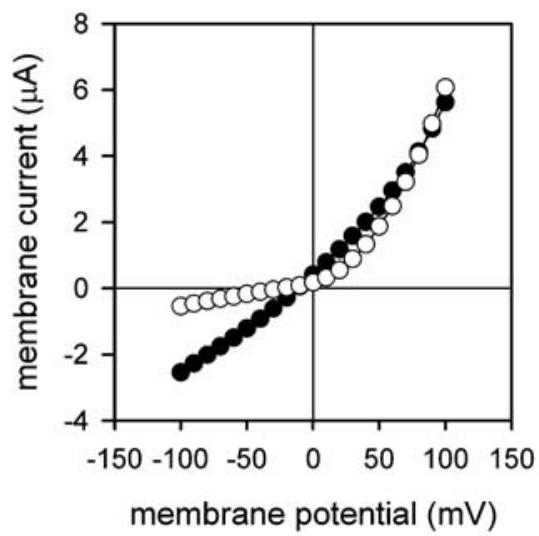

b

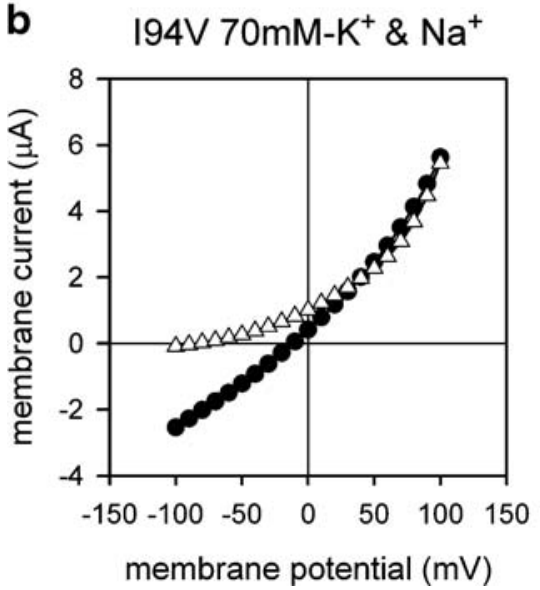

Fig. 7 Mutations of I94 in the consensus sequences of P1. Current voltage relations for the $\mathrm{P} 1$ mutant $\left[94 \mathrm{~V}\right.$ in a $70 \mathrm{mM}\left[\mathrm{K}^{+}\right]_{\mathrm{o}}$ ( filled circle) and in $70 \mathrm{mM}\left[\mathrm{Rb}^{+}\right]_{\mathrm{o}}$ (open circle); and b $70 \mathrm{mM}\left[\mathrm{K}^{+}\right]_{\mathrm{o}}$ ( filled circle) and in $70 \mathrm{mM}\left[\mathrm{Na}^{+}\right]_{\mathrm{o}}$ (open triangle); channels retain some selectivity in this mutant. c and d Current voltage relations for I94S under similar experimental conditions $\left(\mathrm{K}^{+}\right.$, filled circle; $\mathrm{Rb}^{+}$, open
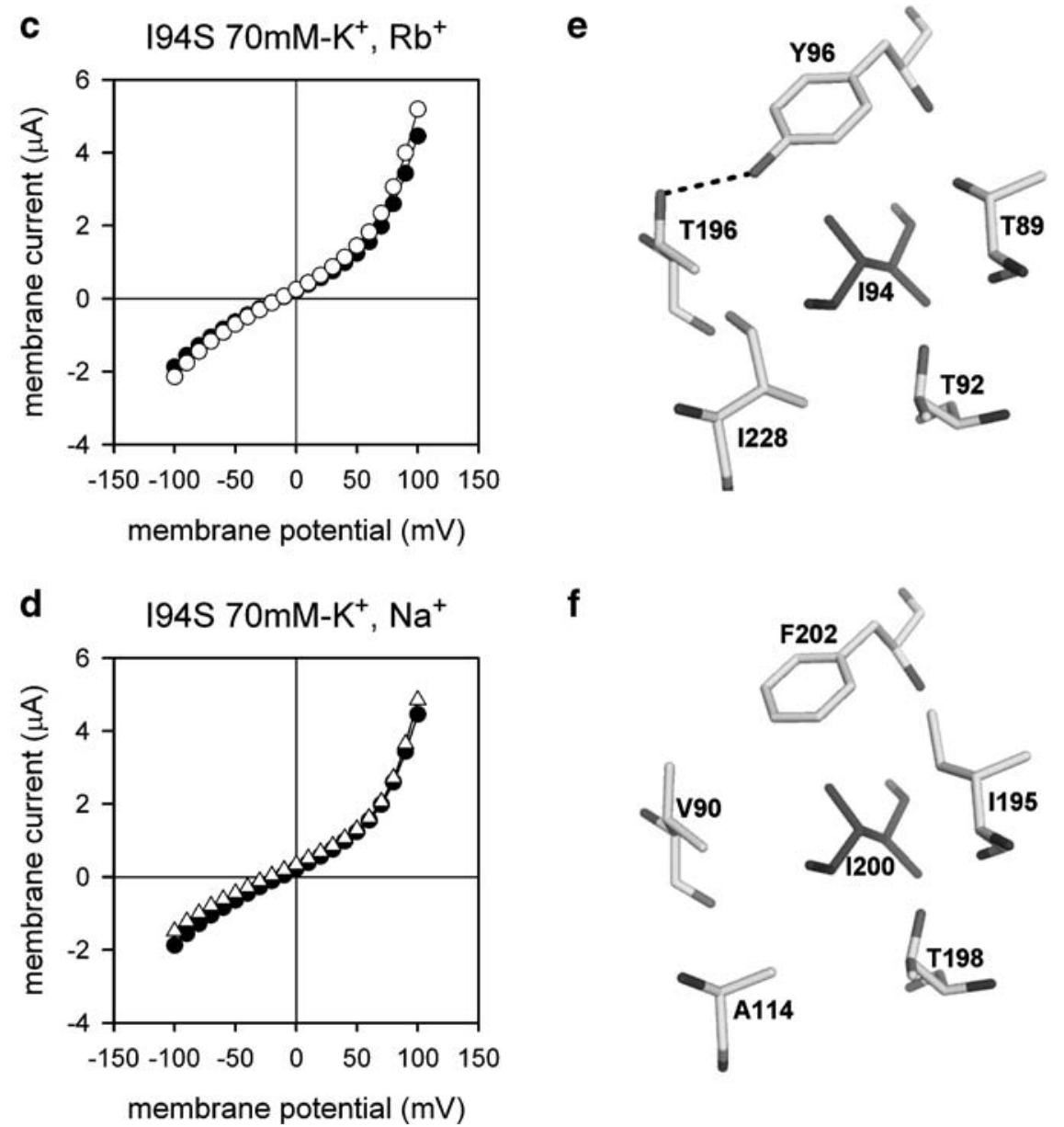

circle; $\mathrm{Na}^{+}$, open triangle); channels lose ionic selectivity with this less conservative mutation. e and f Potential interactions of I94 and its equivalent in P2, I200, suggested by our modelling studies. The residues behind the selectivity filter, surrounding I94 (e); the residues behind the selectivity filter, surrounding I200 (f) 
with mutation of I94. I200L had significantly altered selectivity however (Table 1).

In the model (Fig. 7e,f), I94 points into a hydrophilic pocket and I200 into a hydrophobic pocket. Polar substitutions of 194 (I94S, I94T) may interact with either T92 or T89 in the P1 pore helix. Comparison of crystal structures of KcsA in high and low potassium concentration shows that the equivalent Val in KcsA undergoes conformation change, dependent on $\left[\mathrm{K}^{+}\right]$[57]. Our modelling suggests that, along with backbone deviations, the side chain of I94 also changes conformation, and we anticipate the possibility of a side chain hydrogen bond in the mutants I94S or I94T, which would impede any such change of conformation. As we show below, these mutations both slow the response to voltage and impede shutting under acidification. I200 points principally into a hydrophobic pocket, but in the mutants I200S and I200T, a hydrogen bond may form with T198, also potentially impeding movement.
194 and 200: mutants that alter ionic selectivity affect gating by voltage Mutants of $\mathrm{I} 94$ and I200 where channels show essentially unaltered ionic selectivity (Table 1; Fig. 7) respond to voltage much as wild type channels do (Fig. 8a, I94V). In contrast, mutants of I94 and I200 where selectivity against $\mathrm{Na}^{+}$is reduced (Fig. 8a, I94S) show a slowed response to voltage that is similar to that found in non-selective mutants of $\mathrm{GY}(\mathrm{F}) \mathrm{G}$. Alterations in structure that cause loss of selectivity thus broadly correlate with alterations in the response to voltage.

Mutants of 194 and I200 that alter selectivity also affect the response to acidification When hydrophilic residues (Ser, Thr) replace 194, with the resultant abolition of ionic selectivity, sensitivity to acidification is also lost (Table 2; Fig. 8c). However, replacement of 194 with hydrophobic residues Leu or Val, where channels retain ionic selectivity, results in the retention of a near-wild-type response to acidification (Table 2; Fig. 8b). Mutations of I200 also
Fig. 8 Mutations of 194 gating by voltage and changes in extracellular $\mathrm{pH}$. a Records of currents recorded from oocytes expressing I94V (above) and I94S (below) TASK-1. External solutions contain $70 \mathrm{mM} \mathrm{K}^{+}$, and currents were recorded under voltage steps in increments of $10 \mathrm{mV}$ from a holding potential of $-20 \mathrm{mV}$ to between +100 and $-50 \mathrm{mV}$. b Relationship between the membrane current, normalised to that at $\mathrm{pH}_{\mathrm{o}}=8.5$, (ordinate) and $\mathrm{pH}_{\mathrm{o}}$ (abscissa) for I94V (open circle) and I94L (filled circle), measured at $-40 \mathrm{mV}$. The solid line gives the fit of Eq. 2 to the values at $-40 \mathrm{mV}$, with $\mathrm{p} K_{a}=$ 6.13 for I94V and 7.04 for I94L. For all parts of this figure, the dashed line gives the best fit to wild type at $-40 \mathrm{mV}$ (as in Fig. 6b). c Similar relationships for I94S at $-40 \mathrm{mV}$ (open circle). For I $94 \mathrm{~S}$ at $-40 \mathrm{mV}$, the solid line gives $\mathrm{p} K_{a}=6.54$ (from wild type) and $a=0.08, b=0.92$. d Similar relationships for A100T $-40 \mathrm{mV}$ (open circle). The solid line gives $p K_{\mathrm{a}}=6.64$ (from wild type), $a=0.20, b=$ 0.78 for the fit to $-40 \mathrm{mV}$ a
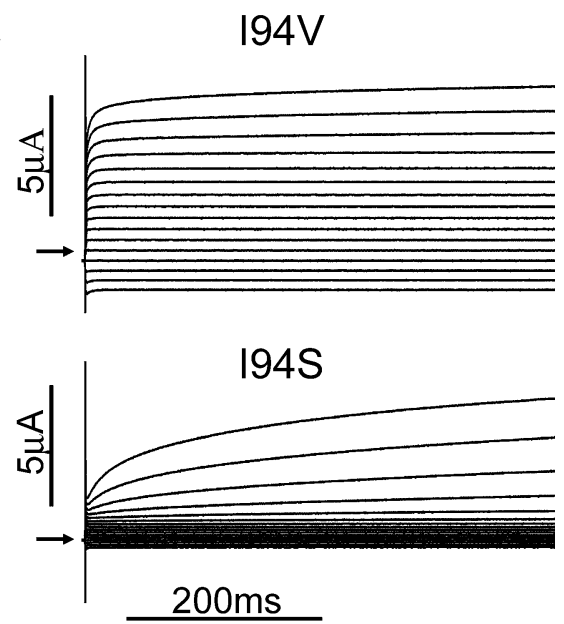

C

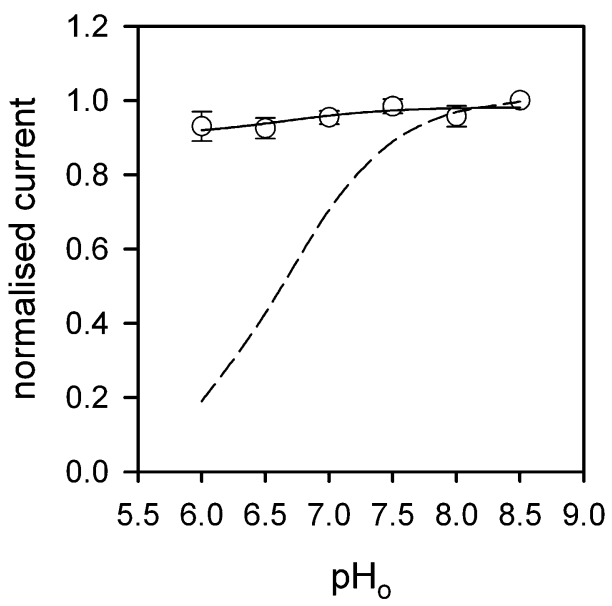

b

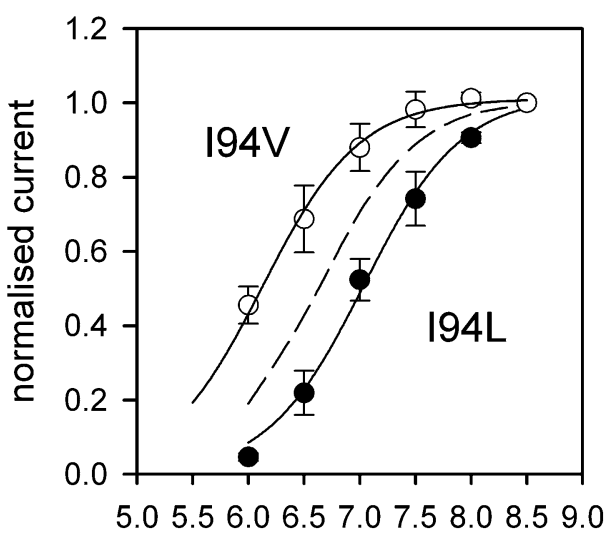

$\mathrm{pH}_{\mathrm{o}}$

d

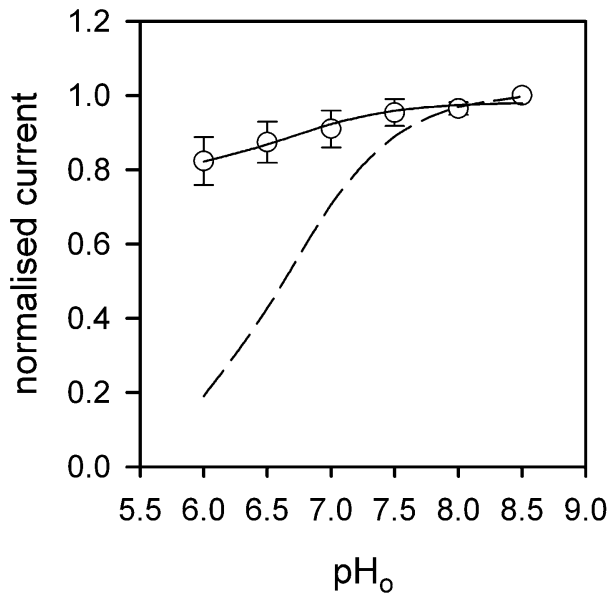


diminish the response to acidification, apparently even in the case of I200V (Table 2).

Evidently disruption of the selectivity filter causes loss of ionic selectivity, a slowing of the response to depolarisation and a loss or radical alteration in acid sensitivity.

Other pore mutants The effects on ionic selectivity and of the response to acidification are documented in Supplementary Tables 1 and 2 .

\section{Mutations of the pore helices}

The pore helix of potassium channels is important in stabilising the selectivity filter, through side chain-side chain interactions [15]. Part of this region contributes to the potassium consensus TxxTxGYG, but the P1 region of TASK-1 differs from most $\mathrm{K}^{+}$channels in having Val in place of the first Thr (position 90; Fig. 1a,c). The preceding residue (position 89, immediately before the consensus sequence) is Thr. Thus, the sequence in TASK-1 is TV, rather than the more conventional VT. We now ask whether this deviation, from a pattern that is strongly conserved in other $\mathrm{K}^{+}$channels, is important for $\mathrm{K}^{+}$channel function in TASK-1.

Table 1 shows the effects of substituting T89 by Val and V90 by Thr. These mutations (T89V and V90T) alter selectivity slightly. Other substitutions of T89 by Ala or, even more conservatively, by Ser or of V90 by Ser do produce significant loss of selectivity against $\mathrm{Na}^{+}$(Table 1). Mutants of V90 (V90L, V90T) have relatively little effect on $\mathrm{pH}$ sensitivity, causing a shift in an alkaline direction (Table 2). The $\mathrm{pH}$ sensitivity of the T89S mutant is close to that of the wild-type channel.

Interestingly however, substitution of T89 with the hydrophobic residues Ala or Val resulted in channels showing behaviour comparable to that seen with Y96F and G97A: substantial current over the physiological range, but an increase in current in alkaline conditions (Table 2). This finding suggests that T89 may play a role in acid sensing by TASK-1.

Mutations of the pore regions - the outer pore mouth

We have already shown that mutations of the putative proton-sensing residue $\mathrm{H} 98$ in $\mathrm{P} 1$ [1, 33, 38] alter the selectivity of TASK-1 ion channels, although they do so with little change in response of currents to voltage (see for example Fig. 4 of [55]). Replacement of the equivalent residue (D204) in P2 also alters ionic selectivity [55]. In the outer mouth of the channel, we have also made mutations
A100T in P1 and V206T in P2 as well as the double mutation A100T/V206T.

We made these mutations initially to test whether introduction of $\mathrm{Thr}$ residues at these positions, mimicking the situation in $\mathrm{Kv}$ channels, would raise the low affinity of TASK-1 for the $\mathrm{K}^{+}$channel blocker tetraethylammonium ion $\left(\mathrm{TEA}^{+}\right)$, but found no detectable blockage of channels by $26 \mathrm{mM}$ or even by $90 \mathrm{mM} \mathrm{TEA}^{+}$in either wild-type or mutant channels (A100T, V206T or A100T/V206T; data not shown). Thus, introduction of a ring of $\mathrm{Thr}$ residues, important for $\mathrm{TEA}^{+}$blockage of Kv channels (T449 in Shaker [35]), does not confer such blockage onto TASK-1.

Both mutations (A100T and V206T) altered ionic selectivity somewhat (Table 1), whereas the double mutation $\mathrm{A} 100 \mathrm{~T} / \mathrm{V} 206 \mathrm{~T}$ gave channels where $\mathrm{Rb}^{+}$was essentially indistinguishable from $\mathrm{K}^{+}$and with substantial permeability for $\mathrm{Na}^{+}$(Table 1). Thus, alteration of the structure, even of the outer mouth of the channel, alters the ionic selectivity of TASK-1.

In $\mathrm{Kv}$ channels, residues in the equivalent positions also regulate C-type inactivation [34], and in TASK-1, the mutants A100T and V206T both show altered $\mathrm{pH}$ sensitivity (Table 2). In the case of A100T, $\mathrm{pH}$ sensitivity is essentially lost (Fig. 8d). Thus, residues in positions similar to those contributing to the regulation of C-type inactivation in $\mathrm{Kv}$ channels also appear to contribute to the regulation of the response to acidification.

\section{Discussion}

We have shown that mutation of residues in the pore regions of TASK-1 modify both channel selectivity and the responses of channels to changes of membrane potential and of extracellular $\mathrm{pH}$. Modification of ionic selectivity is to be expected given the established role of the P-region as selectivity filter. Our experiments confirm that both $\mathrm{P} 1$ and P2 contribute to this process. Further, most positions in these pore regions are tolerant of mutation in that most mutant channels conduct ions. This tolerance may occur partly because point mutations of TASK-1 result in only two residues being replaced at a given level in the selectivity filter, rather than four as in $\mathrm{Kv}$ or Kir. But then, in contrast to the situation with $\mathrm{Kv}$ and Kir channels, most mutations, although producing channels that transported ions, abolished the ability to select among the ions transferred. The rather complex arrangement found in tandem pore channels, with subtle differences between P1 and P2, appears essential for selectivity. Unlike the situation in $\mathrm{Kv}$ and $\mathrm{Kir}$, where the aromatic residue in $\mathrm{GY}(\mathrm{F}) \mathrm{G}$ may be replaced with conservation of $\mathrm{K}^{+}$selectivity [20, 47], even conservative replacements in TASK-1 - Tyr96 by Phe, Phe202 by Tyr-produce TASK channels that are non- 
selective among the monovalent cations studied. However, our results do not support the hypothesis of Chapman et al. [7] that Y96 and D204 in TASK-1 are the principal residues determining ionic selectivity in tandem pore channels. Nor do our results (or those of Lopes et al. [32]; see also [55]) suggest that TASK-1 - with F rather than $\mathrm{Y}$ in the GY(F)G triplet of $\mathrm{P} 2$ - has a less stringent $\mathrm{K}^{+}$selectivity than that of Kv channels [7].

Modification of the pore structure also leads to changes in the response of TASK-1 to voltage. The slowing of the response to depolarisation that occurs with such modification of structure appears reasonably well correlated with effects on ionic selectivity. Appropriate mutation of IGY(F) $\mathrm{G}$ in the pore itself slows the response to voltage and increases the amount of conductance change occurring under depolarisation. Although modified ionic occupancy of the pore may be part of the mechanism, the results are consistent with the response to voltage being associated with a change in the conformation of the pore region. Such a conclusion puts this phenomenon in a class with that of gating at the selectivity filter [4], a class that includes Ctype inactivation in $\mathrm{Kv}$ channels $[34,54]$ and the altered kinetics of Kir channels found in pore mutants [47]. Recently, it has also been shown that voltage dependent gating of KcsA is associated with movements of the selectivity filter [10]. In KcsA, this gating is driven by way of a charged residue (E71), the equivalent of T89 and I195 in TASK-1, which acts as voltage sensor, voltage dependence being lost in the mutant E71C. Although TASK-1 must sense voltage, we have not identified an individual residue playing a voltage-sensing role. Nor have we quantified the equivalent charge associated with the process: This charge is likely to be small [32].

We have also shown that mutations in the pore helix or selectivity filter alter the response of the acid sensitive $\mathrm{K}^{+}$ channel TASK-1 to changes of extracellular $\mathrm{pH}$. It is well established that replacement of His 98 weakens the $\mathrm{pH}$ sensitivity of TASK-1 and TASK-3 and this residue is thought to act as proton sensor [1, 26, 33, 38, 44]. However, substitution of $\mathrm{H} 98$ is not the only replacement of an amino acid residue that causes loss or reduction in $\mathrm{pH}$ sensitivity. Our modelling of the TASK-1 structure indicates that the H98 side chain lies behind the selectivity filter of the channel rather than directly in the ion conduction pathway (Fig. 1c). Thus, protonation of the His side chain cannot simply cause channel blockage; rather, such protonation must initiate a conformational change.

It is likely that this conformational change occurs principally at the selectivity filter. It has already been shown that the response to acidification is dependent on $\left[\mathrm{K}^{+}\right]_{\mathrm{o}}[32]$, suggesting that the permeant cation stabilises the open state, rather as has been described for C-type inactivation in $\mathrm{Kv}$ channels [4, 54]. Involvement of the pore is supported by the fact that mutants of this region reduce or alter the response to acidification. The mutants G95A and I94S/T essentially abolish the response to acidification. In the X-ray structure of the bacterial channel KcsA, residues in the equivalent positions (G77 and V76 in KcsA) adopt different conformations in conducting and non-conducting states of the selectivity filter [57]; this suggests that G95 and 194 similarly adopt different conformations in open and shut states of TASK-1. At the outer mouth of the pore, residues in TASK-1 in positions equivalent to those controlling C-type inactivation in $\mathrm{Kv}$ channels-A100 in P1 and V206 in P2-also help regulate the response to acidification. The mutant A100T is virtually completely unaffected by acidification; the channel appears to be stabilised in an open state in this mutant. On the basis of a likely common mechanism among potassium ion channels, these residues $(\mathrm{G} 95, \mathrm{I} 94, \mathrm{~A} 100)$ are in positions that might be expected to disrupt $\mathrm{pH}$ sensitivity if this response depends on a conformation change of the filter. However, mutations of residues in other positions (Y96, F202, G97, etc) also radically alter the response to voltage.

Certain $\mathrm{Kv}$ channels respond to acidification, and this response is also thought to involve gating at the selectivity filter. Thus, in Shaker channels, extracellular acidification results in a marked acceleration of C-type inactivation [50]. Gating at the filter has also been proposed as the mechanism by which mammalian Kv1.4 [8, 31], 1.5 [23] and 1.3 [48] respond to low $\mathrm{pH}_{\mathrm{o}}$. Again, mutations that inhibit or slow C-type inactivation also inhibit sensitivity to extracellular $\mathrm{pH}$. In these cases, a His residue in the extracellular linker controls entry to the outer mouth of the pore by acting as a proton sensor. This residue is H508 in Kv1.4 [8, 31]. As with H98 in TASK-1, modelling suggests that $\mathrm{H} 508$ lies adjacent to, but not directly in, the ion conduction pathway [8]. A His residue conserved in TASK channels in the M1-P1 linker (residue H72 in TASK-1, -3 and -5 ) is not involved in $\mathrm{pH}$ sensitivity of TASK-3 [26, 44], whereas in TASK-1, the mutant $\mathrm{H} 72 \mathrm{~N}$ has increased acid sensitivity [38]. A gating response to acidification has also been demonstrated for $\mathrm{KCNQ} 2 / 3 \mathrm{~K}^{+}$channels [43]. Thus, the response of TASK channels to acidification may share mechanism with $\mathrm{K}^{+}$channels of the $\mathrm{Kv}$ family.

We propose that $\mathrm{H} 98$ does indeed act as the proton sensor, with its protonation effecting a conformational change of the selectivity filter. The model of the TASK-1 channel suggests a mechanism that may partly explain how this process might occur. In more alkaline conditions, the unprotonated His side chain stabilises a water molecule at the back of the filter through an H-bond, with the water as donor. The water accepts two hydrogen bonds in turn from the backbone amides of Y96 and G97 in the selectivity filter (P1) whilst donating a further bond to the side chain of T89 (whose replacement does indeed alter the response 
to acidification; Table 2). These interactions are illustrated in Supplementary Fig. 2. Protonation of H98 prevents this residue from accepting the hydrogen bond from the water molecule. As a result, the water molecule may be destabilised, reducing its interactions with the backbone of the selectivity filter. A water molecule has similarly been described as stabilising the filter of KcsA in structures from X-ray crystallography [9].

In summary, our results illustrate the effects of a number of pore mutations on ionic selectivity. Both P1 and P2 contribute to selectivity, and the subtle differences that exist between P1 and P2 appear necessary for ionic selectivity. Several mutations that affect ionic selectivity also slow the response of the channel to depolarisation. This response is then likely to be associated with a change in conformation of the pore. So also is the response to acidification, as pore mutations also reduce or radically alter this important physiological response. Our results are consistent with $\mathrm{H} 98$ in the pore mouth acting as a proton sensor. However, such protonation must initiate a gating response that involves conformational change in the selectivity filter of this channel.

Acknowledgements We thank the BBSRC and the Wellcome Trust for support. P.J.S. is supported by a MRC/Novartis CASE Studentship.

\section{References}

1. Ashmole I, Goodwin PA, Stanfield PR (2001) TASK-5, a novel member of the tandem pore $\mathrm{K}^{+}$channel family. Pflügers Arch 442:828-833

2. Bayliss DA, Talley EM, Siros JE, Lei Q (2001) TASK-1 is a highly modulated $\mathrm{pH}$-sensitive 'leak' $\mathrm{K}^{+}$channel expressed in brainstem respiratory neurons. Respir Physiol 129:159-174

3. Bezanilla F, Armstrong CM (1972) Negative conductance caused by entry of sodium and cesium ions into the potassium channels of squid axons. J Gen Physiol 60:588-608

4. Bichet D, Haass FA, Jan LY (2003) Merging functional studies with structures of inward-rectifier $\mathrm{K}^{+}$channels. Nat Rev Neurosci 4:957-967

5. Bockenhauer D, Zilberberg N, Goldstein SAN (2001) KCNK2: reversible conversion of a hippocampal leak into a voltagedependent channel. Nat Neurosci 4:486-491

6. Buckler KJ, Williams BA, Honoré E (2000) An oxygen-, acid- and anaesthetic- sensitive TASK-like background potassium channel in rat arterial chemo-receptor cells. J Physiol 525:135-142

7. Chapman ML, Krovetz HS, VanDongen AMJ (2001) GYGD pore motifs in neighbouring potassium channel subunits interact to determine ion selectivity. J Physiol 530:21-33

8. Claydon TW, Boyett MR, Sivaprasadarao A, Orchard CH (2002) Two pore residues mediate acidosis-induced enhancement of Ctype inactivation of the Kv1.4 $\mathrm{K}^{+}$channel. Am J Physiol 283: C1114-C1121

9. Cordero-Morales JF, Cuello LG, Zhao YX, Jogini V, Cortes DM, Roux B, Perozo E (2006a) Molecular determinants of gating at the potassium-channel selectivity filter. Nat Struct Mol Biol 13:311-318

10. Cordero-Morales JF, Cuello LG, Perozo E (2006b) Voltage dependent gating at the KcsA selectivity filter. Nat Struct Mol Biol 13:319-322
11. Czirják G, Petheo GL, Spat A, Enyedi P (2001) Inhibition of TASK-1 potassium channel by phospholipase C. Am J Physiol 281:C700-C708

12. Czirják G, Toth ZE, Enyedi P (2004) The two-pore domain K channel, TRESK, is activated by the cytoplasmic calcium signal through calcineurin. J Biol Chem 279:18550-18558

13. Decher N, Maier M, Dittrich W, Gassenhuber J, Bruggemann A, Busch AE, Steinmeyer K (2001) Characterization of TASK-4, a novel member of the $\mathrm{pH}$-sensitive, two-pore domain potassium channel family. FEBS Lett 492:84-89

14. DeLano WL (2002) The PyMOL molecular Graphics System http://www.pymol.org

15. Doyle DA, Morais Cabral J, Pfuetzner RA, Kuo A, Gulbuis JM, Cohen SL, Chait BT, MacKinnon R (1998) The structure of the potassium channel: molecular basis of $\mathrm{K}^{+}$conduction and selectivity. Science 280:69-77

16. Duprat F, Lesage F, Fink M, Reyes R, Heurteaux C, Lazdunski M (1997) TASK, a human background $\mathrm{K}^{+}$channel to sense external $\mathrm{pH}$ variations near physiological $\mathrm{pH}$. EMBO J 16:5464-5471

17. Girard C, Duprat F, Terrenoire C, Tinel N, Fosset M, Romey G, Lazdunski M, Lesage F (2001) Genomic and functional characteristics of novel human pancreatic $2 \mathrm{P}$ domain $\mathrm{K}^{+}$channels. Biochem Biophys Res Commun 282:249-256

18. Goldstein SA, Bockenhauer D, O'Kelly I, Zilberberg N (2001) Potassium leak channels and the KCNK family of two-P-domain subunits. Nat Rev Neurosci 2:175-184

19. Hadjú P, Ulens C, Panyi G, Tytgat J (2003) Drug- and mutagenesis-induced changes in the selectivity filter of a cardiac two-pore background $\mathrm{K}^{+}$channel. Cardiovasc Res 58:46-54

20. Heginbotham L, Lu Z, Abramson T, MacKinnon R (1994) Mutations in the $\mathrm{K}^{+}$channel signature sequence. Biophys J 66:1061-1067

21. Jentsch TJ, Poët M, Fuhrmann JC, Zdebik AA (2005) Physiological functions of $\mathrm{CLC} \mathrm{Cl}^{-}$channels gleaned from human genetic disease and mouse models. Ann Rev Physiol 67:779-807

22. Karschin C, Wischmeyer E, Preisig-Muller R, Rajan S, Derst C, Grzeschik KH, Daut J, Karschin A (2001) Expression pattern in brain of TASK-1, TASK-3, and a tandem pore domain $\mathrm{K}^{+}$channel subunit, TASK-5, associated with the central auditory nervous system. Mol Cell Neurosci 18:632-648

23. Kehl SJ, Eduljee C, Kwan DC, Zhang S, Fedida D (2002) Molecular determinants of the inhibition of human Kv1.5 potassium currents by external protons and $\mathrm{Zn}^{2+}$. J Physiol 541:9-24

24. Kim D, Fujita A, Horio Y, Kurachi Y (1998) Cloning and functional expression of a novel cardiac two-pore background $\mathrm{K}^{+}$ channel (cTBAK-1). Circ Res 82:513-518

25. Kim D, Gnatenco C (2001) TASK-5, a new member of the tandem-pore $\mathrm{K}^{+}$channel family. Biochem Biophys Res Commun 284:923-930

26. Kim Y, Bang H, Kim D (2000) TASK-3 a novel member of the tandem pore $\mathrm{K}^{+}$channel family. J Biol Chem 275:9340-9347

27. Lauritzen I, Zanzouri M, Honore E, Duprat F, Ehrengruber MU, Lasdunski M, Patel AJ (2003) $\mathrm{K}^{+}$-dependent cerebellar granule neuron apoptosis. Role of TASK leak $\mathrm{K}^{+}$channels. J Biol Chem 278:32068-32076

28. Leonoudakis D, Gray AT, Winegar BD, Kindler CH, Harada M, Taylor DM, Chavez RA, Forsayeth JR, Yost CS (1998) An open rectifier potassium channel with two pore domains in tandem cloned from rat cerebellum. J Neurosci 18:868-877

29. Lesage F, Lazdunski M (2000) Molecular and functional properties of two-pore-domain potassium channels. Am J Physiol Renal Physiol 279:F793-F801

30. Lesage F, Reyes R, Fink M, Duprat F, Guillemare E, Lazdunski M (1996) Dimerization of TWIK-1 $\mathrm{K}^{+}$channel subunits via a disulfide bridge. EMBO J 15:6400-6407

31. Li X, Bett GC, Jiang X, Bondarenko VE, Morales MJ, Rasmusson RL (2003) Regulation of N- and C-type inactivation of Kv1.4 by 
$\mathrm{pH}_{\mathrm{o}}$ and $\mathrm{K}^{+}$: evidence for transmembrane communication. Am $\mathrm{J}$ Physiol 284:H71-H80

32. Lopes CMB, Gallagher PG, Buck ME, Butler MH, Goldstein SAN (2000) Proton block and voltage gating are potassium dependent in the cardiac leak channel Kcnk3. J Biol Chem 275:16969-16978

33. Lopes CMB, Zilberberg N, Goldstein SAN (2001) Block of Kcnk3 by protons. J Biol Chem 276:24449-24452

34. Lopez-Barneo J, Hoshi T, Heinemann SH, Aldrich RW (1993) Effects of external cations and mutations in the pore region on C-type inactivation of Shaker potassium channels. Receptors Channels 1:61-71

35. MacKinnon R, Yellen G (1990) Mutations affecting TEA blockade and ion permeation in voltage-activated $\mathrm{K}^{+}$channels. Science 250:276-279

36. McGuffin LJ, Bryson K, Jones DT (2000) The PSIPRED protein structure prediction server. Bioinformatics 16:404-405

37. Maingret F, Honoré E, Lazdunski M, Patel AJ (2002) Molecular basis of the voltage dependent gating of TREK-1, a mechano-sensitive $\mathrm{K}^{+}$channel. Biochem Biophys Res Comm 292:339-346

38. Morton MJ, O'Connell AD, Sivaprasadarao A, Hunter M (2003) Determinants of $\mathrm{pH}$ sensing in the two-pore domain $\mathrm{K}^{+}$channels TASK-1 and -2. Pflügers Arch 445:557-583

39. O'Connell AD, Morton MJ, Sivaprasadarao A, Hunter M (2004) Selectivity and interactions of $\mathrm{Ba}^{2+}$ and $\mathrm{Cs}^{+}$with wild-type and mutant TASK1 $\mathrm{K}^{+}$channels expressed in Xenopus oocytes. J Physiol 562:687-696

40. Passmore G (2003) Structure-function studies of inwardly rectifying potassium channels. Ph.D. Thesis, University of Leicester

41. Patel AJ, Honoré E (2001) Properties and modulation of mammalian 2P domain $\mathrm{K}^{+}$channels. Trends Neurosci 24:339-346

42. Pei L, Wiser O, Slavin A, Mu D, Powers S, Jan LY, Hoey T (2003) Oncogenic potential of TASK3 (Kenk9) depends on $\mathrm{K}^{+}$ channel function. Proc Natl Acad Sci 100:7803-7807

43. Prole DL, Lima PA, Marrion NV (2003) Mechanisms underlying modulation of neuronal KCNQ2/KCNQ3 potassium channels by extracellular protons. J Gen Physiol 122:775-793

44. Rajan S, Wischmeyer E, Xin Liu G, Preisig-Muller R, Daut J, Karschin A, Derst C (2000) TASK-3, a novel tandem pore domain acid-sensitive $\mathrm{K}^{+}$channel. An extracellular histidine as $\mathrm{pH}$ sensor. J Biol Chem 275:16650-16657

45. Reyes R, Duprat F, Lesage F, Fink M, Salinas M, Farman N, Lazdunski M (1998) Cloning and expression of a novel $\mathrm{pH}-$ sensitive two pore domain $\mathrm{K}^{+}$channel from human kidney. J Biol Chem 273:30863-30869

46. Sali A, Blundell TL (1993) Comparative protein modelling by satisfaction of spatial restraints. J Mol Biol 234:779-815

47. So I, Ashmole I, Davies NW, Sutcliffe MJ, Stanfield PR (2001) The $\mathrm{K}^{+}$channel signature sequence of murine Kir2.1: mutations that affect microscopic gating but not ionic selectivity. J Physiol 531:37-50

48. Somodi S, Varga Z, Hadju P, Starkus JG, Levy DI, Gaspar R, Panyi G (2004) pH-dependent modulation of Kv1.3 inactivation: role of His399. Am J Physiol 287:C1067-C1076

49. Stanfield PR, Nakajima S, Nakajima Y (2002) Constitutively active and G-protein coupled inward rectifier $\mathrm{K}^{+}$channels: Kir2.0 and Kir3.0. Rev Physiol Biochem Pharmacol 145:47-179

50. Starkus JG, Varga Z, Schonherr R, Heinemann SH (2003) Mechanisms of the inhibition of Shaker potassium channels by protons. Pflügers Arch 447:44-54

51. Taglialatela M, Drew LA, Kirsch GE, de Biasi M, Hartmann HA, Brown AM (1993) Regulations of $\mathrm{K}^{+} / \mathrm{Rb}^{+}$selectivity and internal TEA blockade by mutations at a single site in $\mathrm{K}^{+}$pores. Pflügers Arch 423:104-112

52. Tosatto SC, Bindewald E, Hesser J, Manner R (2001) A divide and conquer approach to fast loop modelling. Protein Eng 15:279-286

53. Wood ZA, Poole LB, Karplus PA (2001) Structure of intact AhpF reveals a mirrored thioredoxin-like active site and implies large domain rotations during catalysis. Biochemistry 40:3900-3911

54. Yellen G (1998) The moving parts of voltage-gated ion channels. Q Rev Biophys 31:239-295

55. Yuill KH, Ashmole I, Stanfield PR (2004) The selectivity filter of the tandem pore potassium channel TASK-1 and its $\mathrm{pH}$ sensitivity and ionic selectivity. Pflügers Arch 448:63-69

56. Zilberberg N, Iloan N, Goldstein SAN (2001) KCNK0: opening and closing the 2-P-domain potassium leak channel entails ' $\mathrm{C}$ type' gating of the outer pore. Neuron 32:635-648

57. Zhou Y, Morais-Cabral JH, Kaufman A, MacKinnon R (2001) Chemistry of ion coordination and hydration revealed by a $\mathrm{K}^{+}$ channel-Fab complex at $2.0 \AA$ resolution. Nature 414:23-24 